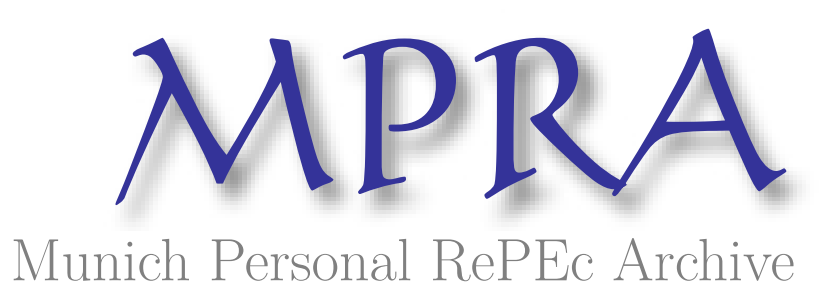

Financial Frictions on Capital Allocation: A Transmission Mechanism of TFP Fluctuations

Chen, Kaiji and Song, Zheng

14 April 2009

Online at https://mpra.ub.uni-muenchen.de/15211/

MPRA Paper No. 15211, posted 14 May 2009 07:27 UTC 


\title{
Financial Frictions on Capital Allocation: A Transmission Mechanism of TFP Fluctuations*
}

\author{
Kaiji Chen ${ }^{\dagger}$ \\ University of Oslo
}

\author{
Zheng Song $g^{\ddagger}$ \\ Fudan University
}

This version: April 14th, 2009

\begin{abstract}
This paper provides a theory of financial frictions as a transmission mechanism for primitive shocks to translate into aggregate TFP fluctuations. In our model, financial frictions distort existing capital allocation across different production units, rather than investment in new capital. News shocks on future technology improvement are introduced as a device to identify TFP fluctuations originating from this mechanism. Our simulation shows that variations in financial frictions in response to news shocks can generate sizable fluctuations in aggregate TFP and, thus, business cycles before the actual technology change is realized. Using a combined dataset from Compustat and IBES, we find that the empirical responses of capital acquisition to prospects about future profitability are significantly larger for firms more likely to be financially constrained, while such a pattern does not exist for new capital investment. Furthermore, capital acquisition of constrained firms is found to be more procyclical than that for unconstrained ones. Our evidence thus provides strong support for the importance of financial frictions on capital allocation as the transmission mechanism proposed by our theory.
\end{abstract}

JEL Classification: E32, G34

Keywords: Financial Friction, Capital Reallocation, TFP Fluctuation, News Shock

${ }^{*}$ We would like to thank Steve Bond, Jean-Pierre Danthine, Mike Golosov, John Hassler, Asye Imrohoroglu, Timothy Kehoe, Stephen Parente, Vincenzo Quadrini, Adriano Rampini, José Victor Rios-Rull, Kjetil Storesletten, Cheng Wang, Fabrizio Zilibotti and seminar participants in Federal Reserve Bank of Cleveland, Hong Kong University of Science and Technology, University of Hong Kong, University of Southern California, Stockholm School of Economics, Uppsala University, University of Zurich, 2007 Annual Meetings of the Society for Economic Dynamics, 2007 Mid-west Macro Meetings, 2007 North American Summer Meeting of the Econometric Society, II REDg Workshop on Dynamic General Equilibrium Macroeconomics, 1st Nordic Summer Symposium in Macroeconomics and 2007 SAET Conference on Current Trends in Economics for helpful comments. We thank YiKai Wang for excellent research assistance. A previous version of the paper was entitled "Financial Friction, Capital Reallocation and Expectation-Driven Business Cycles".

${ }^{\dagger}$ Department of Economics, University of Oslo, Box 1095, Blindern, 0371 Oslo, Norway. Phone: (+47) 22855495. Email: kaijic@econ.uio.no

${ }^{\ddagger}$ School of Economics, Fudan University, Shanghai 200433, China. Phone: (+86) 2165643514. Email: zsong@fudan.edu.cn 


\section{Introduction}

Macroeconomists have long searched for factors behind aggregate Total Factor Productivity (TFP). In particular, a theory of TFP fluctuations has been called for, due to their key role in business cycles. ${ }^{1}$ One promising candidate for understanding TFP fluctuations is financial friction on inputs. The presence of such friction naturally distorts resource allocation and, thus, reduces aggregate productive efficiency. In fact, the business cycle literature has long emphasized the distortion by financial frictions on new capital investment. Recent evidence, however, points to a different channel for financial frictions to affect resource allocation: distorting existing capital allocation across firms. For example, Harford (2005) has shown that variations in financial frictions are crucial for capital reallocation through mergers and acquisitions. Reallocation at the disaggregate level, furthermore, has been found to play a key role in explaining U.S. aggregate productivity fluctuations over business cycles (e.g., Basu and Fernald, 2001). Taken together, these observations indicate that variations in financial frictions, by reallocating capital at the disaggregate level, might be important as a transmission mechanism for primitive shocks to translate into aggregate TFP fluctuations.

This paper formalizes the above idea from both theoretical and empirical perspectives. We first construct a model in which financial frictions affect aggregate productive efficiency via capital allocation across different production units (projects). We then introduce news shocks on future technological improvement as a device to identify aggregate TFP fluctuations originating from variations in financial frictions. These shocks are, by construction, uncorrelated to the current production technology, but, at the same time, they affect financial frictions through future profitability. Accordingly, the adoption of news shocks allows us to isolate and identify at firm level variations in credit conditions that are uncorrelated with changes in current technology, a prerequisite to test the roles of financial frictions later in the paper using firm-level data. Our theory shows that endogenous variations of financial frictions in response to such primitive shocks can trigger aggregate TFP fluctuations and business cycles through reallocating capital.

The key ingredient of our model is asymmetric financing constraint across projects. In our

\footnotetext{
${ }^{1}$ For example, Chari, Kehoe and McGrattan (2007) suggest that fluctuations in aggregate TFP account for most of the post-war business cycle fluctuations. They even claim that a fall in TFP is key in explaining the output decline during the Great Depression. Cole and Ohanian (1999) reach similar conclusions, arguing that a sharp decline in TFP is key to explain the output drop during the Great Depression. Also, Arias, Hansen and Ohanian (2007) claim that a decline in the volatility of TFP can successfully account for the decline in the cyclical volatility of output and its components since 1983.
} 
economy, there are two types of projects: One is subject to a binding financial constraint on the project scale due to limited enforcement of debt payment by entrepreneurs, and the other is not. Given the non-default of the debt contract, debt, and thus, the production scale of a constrained project are limited to a fraction of the future contract value for the entrepreneur. The asymmetry of financial constraints implies a gap of marginal product of capital across different types of projects, which creates a potential efficiency gain of reallocating capital from unconstrained to constrained projects.

As a result, any primitive shock that affects the future contract value may help to trigger aggregate TFP fluctuations through variations in financial frictions. Candidates for such shocks include news shocks on future technological improvement. Specifically, the arrival of good news causes an immediate jump in the value of the contract by increasing future profitability of the constrained projects. Entrepreneurs, therefore, have less incentive to default on the debt payment. This weakens the financial constraint and induces capital to flow to constrained projects. The efficiency gain arising from capital reallocation shows up in the aggregate economy as an upward shift to current aggregate TFP, and leads to business cycles by allowing positive comovement among current output, consumption, investment, and hours worked. ${ }^{2}$

To evaluate the quantitative implications of our model, we calibrate the economy to the U.S. data. Simulation results indicate that our proposed transmission mechanism of TFP fluctuations can be quantitatively important. In particular, the magnitude of the increase in TFP on impact to a positive news shock, which is purely driven by a reallocation of capital, is about one third of the increase in TFP when technology improvement is materialized. Such a magnitude is in line with the impulse response of TFP to innovations to stock prices, as documented by Beaudry and Portier (2006). Moreover, business cycle moments of the economy are close to those in the U.S. data. This suggests that our model can replicate the U.S. business cycles reasonably well.

Our theory delivers the following two testable implications regarding our proposed transmission mechanism. First, financial frictions on capital allocations are countercyclical. In other words, we should expect that during an economic expansion (recession), financially constrained firms acquire more (less) capital than unconstrained ones. Second, firm-level variations in expected future profitability affect capital reallocation for financially constrained firms. By contrast, there is no such effect for unconstrained firms. In our model, the first implication

\footnotetext{
${ }^{2}$ Throughout this paper, we explore the effects of positive news shocks on TFP to illustrate the role of financial frictions as a transmission mechanism. Our proposed mechanism, however, can also be applied to the TFP dynamics during an economic downturn.
} 
provides a channel for financial frictions on capital allocation to affect aggregate TFP at the business cycle frequency, while the second serves as the underlying mechanism for news shocks to affect capital reallocation and, thus, as the micro-foundation for the countercyclicality of frictions on capital allocation.

We use a combined data set from Compustat and IBES to test the above two implications. We first classify firms into quintiles according to the likelihood of being financial constrained, using the method of Kaplan and Zingales (1997). We find that firms in the top quintiles acquire more capital in boom than those in the bottom quintiles do, while the opposite is true for recession. We then use analyst earnings forecast as a proxy for individual firms' prospects for future profitability. Our panel regression shows that the elasticity of capital acquisition to earnings forecast is monotonically increasing in the likelihood of being financial constrained. Our empirical results therefore strongly support both implications and, therefore, our theory.

Finally, we examine the empirical relevance of a competing channel for business prospects to affect firms' production scale and, thus, business cycles: financial frictions on new capital investment. This channel has been widely adopted in the literature to explain business cycle propagation. ${ }^{3}$ We find that the estimated elasticities of investment to earnings forecast are very similar in magnitude across quintiles, suggesting that variations in financial frictions are not likely to be important in investment fluctuations over the business cycles. This, together with our empirical findings for capital acquisition, indicates a more empirically plausible role of financial frictions on capital allocation as a transmission mechanism for aggregate TFP fluctuations.

Our model is closely related to Jermann and Quadrini (2007). They argue that in an economy with financial frictions due to limited enforcement of debt repayment, the mere prospect of high future productivity growth can generate sizable gains in labor productivity through resource reallocation. In their model, however, financial frictions are imposed on the investment of new capital goods. Like other models focusing on frictions distorting saving-investment decisions (referred to as "investment wedge"), variations in such frictions in response to primitive shocks cannot affect productive efficiency on impact. Moreover, a relaxation of the financial constraint induces capital and labor to shift from the consumption good to the investment good sector, implying that consumption and investment comove negatively. ${ }^{4}$ In our model, by

\footnotetext{
${ }^{3}$ See, among others, Kiyotaki and Moore (1997), Bernanke, Gertler, and Gilchrist (1998) and Cooley, Marimon and Quadrini (2004).

${ }^{4}$ The negative correlation between consumption and investment is also present in other existing studies. Beaudry and Portier (2007) have proved that in a two-sector model with constant returns to scale for production, an increase in investment is necessarily associated with a decrease in consumption or hours worked or both. We extended the proof to two-sector models with decreasing returns to scale in one sector or both and financial
} 
contrast, relaxing the financial constraint can trigger an immediate expansion of TFP by reallocating existing resources. This makes the positive comovement of macro aggregates feasible.

This paper contributes to the literature on financial frictions. It has long been argued that frictions in financial markets are important for business cycles. For example, Bernanke and Gertler (1989), Kiyotaki and Moore (1997) and many other studies show that the presence of financial frictions adds persistence or volatility to aggregate fluctuations over business cycles. ${ }^{5}$ More recently, researchers started to pay attention to the role of improving financial markets on Great Moderation (see, for example, Jermann and Quadrini, 2006). Despite this widely accepted view on the importance of financial frictions, their effects through distorting investment have been recently found to play quantitatively minor roles in driving economic fluctuations. ${ }^{6}$ Our paper provides a new insight into the role of financial frictions over business cycles. To our knowledge, we are the first to show, both theoretically and empirically, that financial frictions on capital allocation, instead of new capital investment, may serve as a key transmission mechanism for primitive shocks to translate into aggregate TFP fluctuations.

Moreover, our work contributes to the literature on the empirical relationship between resource reallocation and aggregate productivity fluctuations. Basu and Fernald (2000) find that resource reallocation plays a key role in aggregate productivity fluctuations over business cycles. One channel for resource reallocation to affect aggregate productivity is through the countercyclical frictions on capital reallocation. For example, Maksimovic and Philips (2001) find that less productive firms tend to be sold as prospects of the aggregate economy improve. Correspondingly, aggregate output and the productivity dispersion across firms are found to be negatively correlated (Eisfeldt and Rampini, 2006). ${ }^{7}$ Harford (2005) provides further evidence that the observed correlation between economic expansion and merger waves is essentially driven by an increase in macro-level capital liquidity and a reduction in the degree of financial frictions correlated with stock market valuation. Consistent with Harford's findings, our empirical results may shed light on the countercyclicality of frictions on capital reallocation: A brighter prospect in booms allows financially constrained firms to acquire more capital than unconstrained firms, thus helping to reduce the gap of marginal product of capital across firms.

This paper is related to the literature on credit or liquidity shocks. Although such shocks are often adopted as primitive shocks in theoretical work (e.g., Jermann and Quadrini, 2006 and

frictions on the investment good sector (e.g., Kiyotaki and Moore, 1997). See Section 5.3.2 for the proof.

${ }^{5}$ See Bernanke, Gertler and Gilchrist (1999) for an excellent review of this literature.

${ }^{6}$ For example, business cycle accounting by Chari et al. (2007) suggests that frictions that show up as the investment wedge play, at best, a tertiary role in the Great Depression and the 1982 recession.

${ }^{7}$ Eisfeldt and Rampini (2006) found that the correlation of productivity dispersion with output is around -0.4. This negative correlation is robust to adjustment of capital utilization. Consistent with the empirical finding, the financial friction in our model implies countercyclical benefits for capital reallocation. 
Aghion, Angeletos, Banerjee and Manova, 2007), two problems occur when theory confronts data. First, the endogeneity makes it difficult to isolate variations in credit conditions that are exogenous to shocks to current productivity. ${ }^{8}$ Second, idiosyncratic credit shocks (i.e., tightening or relaxing credit constraint) at the firm level are hard to identify or measure. Our paper shows that the use of news shocks provides a way of overcoming the above two problems. Theoretically, the adoption of news shocks avoids the endogeneity issue, because our theory indicates that news shocks may cause variations in financial frictions, while they are uncorrelated to current technology. Empirically, such news shocks can be proxied by individual firms' earnings forecasts. This allows us to test at the disaggregate level our proposed transmission mechanism through which idiosyncratic credit frictions affect capital allocation.

Our paper also contributes to the recent discussion on the role of news shocks in triggering business cycles. Beaudry and Portier (2007) present a wide class of business cycle models in which mere changes in expectation about future productivity cannot generate comovement among consumption, investment and hours worked. ${ }^{9}$ The reason is essentially the same as that discussed above: Without current expansion of TFP, consumption and investment will always comove negatively if they replace one to one with each other. Den Haan and Kaltenbrunner (2006) provide another example. In that paper, although labor hoarding may translate into additional resources for economic expansion when there are matching frictions in labor market, the initial responses of consumption and investment move in opposite directions. ${ }^{10}$ One potential source of the observed TFP changes in response to news shocks is variations in capital utilization. However, in the standard setup with convex investment adjustment costs, an investment boom must be associated with an increase in marginal $q$, which actually implies a decline in capital utilization. ${ }^{11}$ By contrast, our work shows explicitly how news shocks are transmitted through financial frictions at the disaggregate level into aggregate TFP fluctuations. In particular, both of our theoretical and empirical findings suggest that variations in financial frictions can be considered as a potential transmission mechanism for news shocks to drive business cycles, as claimed by Beaudry and Portier (2006).

Finally, this paper is related to a growing literature on frictions on resource allocation as

\footnotetext{
${ }^{8}$ For example, Eisfeldt (2004) argues that market liquidity varies with productivity shocks. In addition, Eisfelt and Rampini (2006) show in a standard business cycle model that current TFP shocks affect frictions in capital allocation.

${ }^{9}$ Beaudry and Portier (2004) and Danthine, Donaldson and Johnsen (1998) reached similar conclusions.

${ }^{10}$ In addition, Christiano, Motto and Rostagno (2006) find that it is hard to generate expectation-driven business cycles without nominal frictions and monetary targeting.

${ }^{11}$ This holds even if there is an expected investment-good-specific technological improvement. Using "flow" investment adjustment costs, therefore, becomes the key for capital utilization to increase in a boom period (see Jaimovich and Rebelo, 2006).
} 
the source of TFP (e.g., Restuccia and Rogerson, 2008; Barseghyan and Dicecio, 2006; and Erosa and Cabrillana, 2007). Much of the literature emphasizes the role of frictions in the cross-country difference of long-run TFP and, therefore, abstracts from the dynamics of such frictions. Recently, Buera and Shin (2008) show the persistent effect of financial frictions on economic development via resource allocation. Our paper instead explores its role for TFP fluctuations over business cycles.

The paper is organized as follows. In Section 2, we illustrate, in a simple model without labor, that financial frictions on capital allocation may act as a transmission mechanism of TFP fluctuations. We then extend the economy to incorporate more features of business cycles in Section 3. Section 4 provides a discussion of the calibration procedure. In Section 5, we report the impulse responses and business cycle statistics, and we check the robustness of our model to alternative parameter values. Using firm-level data, Section 6 tests the transmission mechanism in our model for news shocks to affect aggregate productivity via capital reallocation. Section 7 concludes. The appendix contains the definition for recursive competitive equilibrium and the derivation of the enforcement constraint.

\section{A model without labor}

In this section, we describe a model that abstracts from labor as input into production (referred to as "economy without labor") to highlight the role of financial frictions on capital allocation as a transmission mechanism of aggregate TFP fluctuations. ${ }^{12}$ A full-blown model with richer business cycle ingredients will be provided in the following section.

Consider an economy with a representative household and a continuum of entrepreneurs with unit mass. The representative household owns physical capital and decides how much to consume and how much to invest in capital. In addition, the representative household owns the entitlement and, therefore, the profit from a continuum of projects. Entrepreneurs have access to the technology of operating projects. Each entrepreneur can operate only one project. Entrepreneurs decide how much capital to rent from the representative household for profit maximization. ${ }^{13}$

Projects are classified into two categories, according to whether working capital (or liquid fund) is needed for production. Specifically, a fraction $\eta$ of projects, denoted as type- $h$ projects,

\footnotetext{
${ }^{12}$ Alternatively, this model can be interpreted as one in which labor is a fixed factor in production and is supplied inelastically.

${ }^{13} \mathrm{By}$ assuming rental markets as the avenue to allocate existing capital, we abstract from the issue of firm dynamics in the context of business cycles. Such an abstraction, however, will not affect the qualitative feature of our model. As we will show later, the key determinant of aggregate TFP is the distribution of capital across different projects.
} 
require working capital before production takes place. We assume that the size of the working capital required, denoted as $D\left(K_{t}^{h}\right)$, increases with the size of the capital deployed in a type- $h$ project, denoted as $K_{t}^{h}$. For the remaining $1-\eta$ fraction of projects, referred to as type- $l$ projects, working capital is not necessary. ${ }^{14}$

Entrepreneurs retain the ability to operate the project with probability $\phi$. Once she loses this ability, the entrepreneur exits the market with no cost, and there will be a new entrepreneur entering the market and starting with the same type of project as her predecessor. This assumption, together with the law of large numbers, enables the fraction of each type of projects to be constant over time.

\subsection{Project Financing and the Entrepreneur's Problem}

Type- $h$ projects are financed through optimal contracts with limited enforceability à la Jermann and Quadrini (2006). To finance working capital, entrepreneurs of type- $h$ projects borrow from an outside lender at the beginning of each period and repay the debt at the end of the period, after all transactions are completed. ${ }^{15,16}$ As an intra-period loan, it has a zero net interest payment. The ability to borrow, however, is bounded by the limited enforcement of the debt repayment. At the end of the period, the entrepreneur has the ability to divert working capital. Once the entrepreneur defaults, the lender can take over the control right of the project from the entrepreneur and recover a fraction $\varphi(<1)$ of the future project value. The entrepreneur and the lender can then renegotiate repayment of the debt. Section 8.1 of the appendix describes the renegotiation process in detail and shows that the incentive-compatibility condition imposes the following financial constraint

$$
D\left(K_{t}^{h}\right) \leq \theta V_{t+1}^{h}=\theta E_{t} \sum_{j=1}^{\infty} \hat{\beta}^{j} \pi_{t+j}^{h}
$$

where $V_{t+1}^{h}$ is the value of a type- $h$ project to the entrepreneur at the end of period $t .{ }^{17} \hat{\beta} \equiv \beta \phi$ is the effective discount factor and $\beta$ is the subjective discount factor. $\pi_{t+j}^{h}$ is the one-period profit of a type- $h$ project at period $t+j$. (1) implies that the entrepreneur can borrow up to

\footnotetext{
${ }^{14}$ Assuming that working capital is also required for type- $l$ projects does not affect our qualitative results, so long as the degree of financial constraint is different across different types of projects.

${ }^{15}$ The assumption for entrepreneurs to borrow working capital each period can be rationalized by the fact that because entrepreneurs become tempted to use excess internal funds inefficiently, it is costly for firms to retain operating cash flows (see Jensen, 1986). We extend the model to allow internal liquid asset accumulation, which could be used to partially finance working capital. Our results below are robust to this extension. Details are available upon request.

${ }^{16}$ One example of such outside lenders can be a financial intermediary issuing production loans each period.

${ }^{17}$ Our implicit assumption here is that if the entrepreneur chose to default, the working capital would be diverted to the owner of the projects (e.g., the representative household).
} 
the amount that he can pledge to the lender, which is a fraction $\theta$ of the future project value. ${ }^{18}$

The production technology of a type- $i, i \in\{h, l\}$, is given by

$$
Y_{t}^{i}=Z_{t}\left(K_{t}^{i}\right)^{\alpha}
$$

where $K_{t}^{i}$ is capital in a single type- $i$ project. $Z_{t}$ is the aggregate technology, which follows a stochastic process, as will be described later.

At each period, the entrepreneur of a type- $h$ project chooses capital $K_{t}^{h}$ for profit maximization.

$$
\max _{K_{t}^{h}} Z_{t}\left(K_{t}^{h}\right)^{\alpha}-\left(r_{t}+\delta\right) K_{t}^{h},
$$

subject to (1). It should be noted that the entrepreneur's problem can be alternatively specified as maximizing the present discounted project profit subject to the sequence of financial constraints (1), by choosing the whole path of capital. The assumption of the rental market for capital, however, makes the choice of capital at each period independent of previous choices. Therefore, the dynamic problem boils down to the sequence of one-period profit-maximization problems, as stated in (3).$^{19}$

The problem of an entrepreneur of a type-l project is

$$
\max _{K_{t}^{l}} Z_{t}\left(K_{t}^{l}\right)^{\alpha}-\left(r_{t}+\delta\right) K_{t}^{l}
$$

The first-order condition delivers the standard demand equation of capital

$$
K_{t}^{l}=\left(\frac{\alpha Z_{t}}{r_{t}+\delta}\right)^{\frac{1}{1-\alpha}}
$$

We measure the degree of frictions on capital allocation as the gap of marginal product to capital ( $M P K$ henceforth) between two types of projects.

$$
\frac{M P K_{t}^{h}}{M P K_{t}^{l}}=\left(\frac{K_{t}^{h}}{K_{t}^{l}}\right)^{\alpha-1}
$$

In this simple model, such frictions originate from the presence of financial constraint on type $-h$ projects. Accordingly, tightening (or relaxing) the financial constraint leads to an increase (or decrease) in the gap of $M P K$ and, therefore, frictions on capital reallocation.

A more general but reduced-form approach to modeling frictions on reallocating capital is to assume a quadratic cost of reallocating capital. To obtain countercyclicality of such frictions as

\footnotetext{
${ }^{18}$ Section 8.1 of the appendix shows that $\theta$ is positively related to the bargaining power of the lender and the fraction of project value that is recoverable by the lender.

${ }^{19}$ The proof is available upon request.
} 
observed, one might assume that the magnitude of the adjustment cost parameter is negatively correlated with future profitability (see Eisfeldt and Rampini, 2006). Our model can be seen as providing a micro-foundation for frictions on reallocation capital and its countercyclicality, which will be shown below. ${ }^{20}$

\subsection{Aggregate TFP and Primitive Shocks}

In standard Real Business Cycle (RBC henceforth) models, current technological shocks, by construction, are the only source for aggregate TFP fluctuations. Instead, our purpose here is to show that financial frictions, by distorting capital allocation, serve as a source of aggregate TFP fluctuations. To this end, we decompose the aggregate TFP and its fluctuations to shed light on their potential sources in our economy.

We measure the aggregate TFP as the "Solow Residual." In our economy, aggregate output can be expressed as

$$
\begin{aligned}
Y_{t} & =\eta Z_{t}\left(K_{t}^{h}\right)^{\alpha}+(1-\eta) Z_{t}\left(K_{t}^{l}\right)^{\alpha} \\
& =T F P_{t} K_{t}^{\alpha}
\end{aligned}
$$

where

$$
T F P_{t}=\frac{\eta Z_{t}\left(K_{t}^{h}\right)^{\alpha}+(1-\eta) Z_{t}\left(K_{t}^{l}\right)^{\alpha}}{K_{t}^{\alpha}}
$$

Accordingly, the percentage deviation of aggregate TFP from its steady-state value can be expressed as

$$
\triangle \log T F P_{t}=\triangle \log \left(\eta Z_{t}\left(\frac{K_{t}^{h}}{K_{t}}\right)^{\alpha}+(1-\eta) Z_{t}\left(\frac{K_{t}^{l}}{K_{t}}\right)^{\alpha}\right)
$$

Note that the right-hand-side ("RHS" henceforth) of (7) can be further decomposed as

$$
\begin{aligned}
& \triangle \log \left(\eta Z_{t}\left(\frac{K_{t}^{h}}{K_{t}}\right)^{\alpha}+(1-\eta) Z_{t}\left(\frac{K_{t}^{l}}{K_{t}}\right)^{\alpha}\right) \\
= & \underbrace{\left.\triangle \log \left(\eta Z_{t}\left(\frac{K_{t}^{h}}{K_{t}}\right)^{\alpha}+(1-\eta) Z_{t}\left(\frac{K_{t}^{l}}{K_{t}}\right)^{\alpha}\right)\right|_{\frac{K_{t}^{i}}{K_{t}}=\frac{K^{i}}{\bar{K}}}}_{\text {the technological effect }} \\
& +\underbrace{\left.\triangle \log \left(\eta Z_{t}\left(\frac{K_{t}^{h}}{K_{t}}\right)^{\alpha}+(1-\eta) Z_{t}\left(\frac{K_{t}^{l}}{K_{t}}\right)^{\alpha}\right)\right|_{Z_{t}=\bar{Z}}}_{\text {the reallocation effect }} \\
& + \text { cross product terms }
\end{aligned}
$$

\footnotetext{
${ }^{20}$ Other frictions for capital reallocation include managerial incentive to relinquish the control of productive assets when types of managers are private information (see Eisfeldt and Rampini, 2008a).
} 
Steady-state values are marked by upper bars. The first argument on the RHS of (8), called "the technological effect," captures the effect of exogenous technological shifts on the aggregate TFP, given the distribution of capital as in the steady state. The second argument, referred to as "the reallocation effect," captures the effect of changes in the distribution of capital across different types of projects, given the technology as in the steady state. In this simple economy, the first-best allocation involves an equal amount of capital allocated across projects. Introducing financial frictions may lead to inefficient capital allocation and, hence, reduce aggregate productive efficiency.

Our purpose is to isolate TFP fluctuations caused by the reallocation effect, which in our model originates from the presence of financial frictions. To this end, we would like to introduce primitive shocks that help to trigger capital reallocation, but bear no contemporaneous technological effect. Note that in our model, any primitive shock affecting future profitability of the constrained projects may help to trigger a reallocation of capital by changing the future contract value. One candidate for such shocks is a news shock on future technological change. ${ }^{21}$ Specifically, we assume that the aggregate technology $Z_{t}$ follows

$$
\log Z_{t+1}=(1-\rho) \log \bar{Z}+\rho \log Z_{t}+\epsilon_{t}^{Z}
$$

where $\epsilon_{t}^{Z}$ denotes innovations regarding information on the next-period aggregate technology $Z_{t+1}$. The process (9) is different from the stochastic technology process in standard RBC models: Information on $Z_{t+1}$ arrives at time $t$, before $Z_{t+1}$ is realized. As a result, nextperiod aggregate technology becomes perfectly predictable. Note that the news shock $\epsilon_{t}^{Z}$ is orthogonal to the current technology $Z_{t}$ and, hence, cannot affect the aggregate TFP via the technological effect. Instead, such a news shock leads to variations in financial frictions by changing the value of a type- $h$ project, as it contains information about future technology. The revaluation of financially constrained projects triggers a reallocation of capital. Consequently, the reallocation effect is the only source of TFP fluctuations before actual technology shift is realized.

\subsection{Household}

The representative household solves the following problem

$$
\max _{\left\{C_{t}, K_{t+1}\right\}_{t=0}^{\infty}} E_{0}\left[\sum_{t=0}^{\infty} \beta^{t} \frac{C_{t}^{1-\sigma}-1}{1-\sigma}\right],
$$

\footnotetext{
${ }^{21}$ Another candidate for primitive shocks that will obtain qualitatively similar results is an asset pricing shock arising from the assumption that the entrepreneurial survival probability is itself stochastic.
} 
subject to

$$
\begin{aligned}
C_{t}+I_{t} & =r_{t} K_{t}+(1-\eta) \pi_{t}^{l}+\eta \pi_{t}^{h} . \\
K_{t+1} & =(1-\delta) K_{t}+I_{t},
\end{aligned}
$$

We thus obtain the standard Euler equation.

$$
c_{t}^{-\sigma}=\beta E_{t}\left[c_{t+1}^{-\sigma}\left(1+r_{t+1}\right)\right]
$$

\subsection{Timing and Information}

The events within each period proceed as follows. At the beginning of each period, news regarding future technological opportunity arrives. Meanwhile, the previous-period news on the current-period technology is materialized. Then, the stand-in household supplies capital to entrepreneurs. After production takes place, the household receives factor payments and profits, and makes consumption-saving choices. Finally, uncertainty about entrepreneurial survival is revealed.

\subsection{Calibration}

We proceed to calibrate the model. ${ }^{22}$ One period in our model corresponds to one calendar year, the frequency adopted by Eisfeldt and Rampini (2006) in their measurement of the magnitude of capital reallocation. Consistent with their measurement, we calculate the size of aggregate capital reallocation in our model by

$$
\hat{K}_{t} \equiv \frac{\eta\left|K_{t}^{h}-K_{t-1}^{h} \frac{K_{t}}{K_{t-1}}\right|+(1-\eta)\left|K_{t}^{l}-K_{t-1}^{l} \frac{K_{t}}{K_{t-1}}\right|}{K_{t}} .
$$

Note that $\hat{K}_{t}$ measures the sum of changes of capital position for individual projects net of new capital investment, as the previous period capital stocks in each project are adjusted by changes in the aggregate capital stock. To obtain a quantitative assessment of the model, we parameterize $D\left(K_{t}^{h}\right)$ as follows:

$$
D\left(K_{t}^{h}\right)=\left(K_{t}^{h}\right)^{\gamma}
$$

where $\gamma \in[0,1]$, which can be interpreted as the elasticity of working capital required with respect to the scale of physical capital. In the following calibration, $\gamma$ is a key parameter targeting the size of capital reallocation over business cycles.

\footnotetext{
${ }^{22} \mathrm{~A}$ formal definition of the competitive equilibrium in a more general model is provided in the next section. The numerical strategy adopts the standard recursive method.
} 
We set $\sigma=1$, which corresponds to the case of logarithmic utility. $\alpha$ is set to be 0.4 to map into a capital income share of 0.4 . Also, we set $\delta=0.1$, as in the literature. $\beta=0.96$ such that a steady state real interest rate is 4 percent. We let the entrepreneurial survival probability $\phi$ be 0.90 , which is broadly consistent with the firm survival probability in U.S. data for manufacturing and business service sectors, as reported by OECD (2001).

For parameters governing the technology process, we set $\rho=0.95$ to match a quarterly persistence of 0.987 . The standard deviation of innovation $\sigma_{\epsilon}^{Z}$ is set equal to 1.26 percent such that the standard deviation of the H-P filtered log TFP simulated from the model is equal to the corresponding value from annual U.S. data.

Finally, $\eta, \theta$ and $\gamma$ are chosen to match two relevant observations. First, we target a value of 2 for the ratio of marginal productivity of capital between 75 th- and 25th-percentile projects. ${ }^{23}$ The second target is an average size of capital reallocation of 1.4 percent, the ratio of acquisitions plus sales of PP\&E over assets for a panel of Compustat firms, as estimated by Eisfeldt and Rampini (2006). We choose $\eta=0.5, \theta=0.197$ to match the first observation, and $\gamma=0.40$ to match the second. $\eta=0.5$ is in line with the results of Kaplan and Zingales (1997), who found that about 45 percent of the firms in their sample were likely to be financially constrained. ${ }^{24}$ Moreover, as shall be shown in Section 5.3.1, our quantitative results are robust to different parameterization of $\eta$. Table 1 summarizes parameter values for this economy.

Table 1. Parameterized Values for Economy w/o Labor

\begin{tabular}{clc}
\hline \hline Symbol & \multicolumn{1}{c}{ Definition } & Value \\
\hline \multicolumn{3}{c}{ Technology } \\
$\phi$ & Capital share in production function & 0.40 \\
$\delta$ & Entrepreneurial survival rate & 0.90 \\
$\gamma$ & Depreciation rate for capital & 0.10 \\
$\rho$ & Elasticity of working capital required & 0.40 \\
$\sigma_{\epsilon}^{Z}$ & Autocorrelation coefficient & 0.95 \\
& Standard deviation of information innovation & 0.013 \\
$\beta$ & $\quad$ Discount factor in utility function & 0.96 \\
$\sigma$ & Coefficient of relative risk aversion & 1 \\
& $\quad$ Market & 0.197 \\
$\eta$ & Default parameter & 0.50 \\
\hline
\end{tabular}

\footnotetext{
${ }^{23}$ As we will show in the next section, in our full-blown economy, the ratio of marginal productivity of capital between two types of projects are equal to the ratio of labor productivity, which we target to match the corresponding U.S. data.

${ }^{24}$ More specifically, Kaplan and Zingales (1997) develop a criterion to classify firms into groups in terms of likelihood of being financially constraint. They find that among a sample of 49 firms, 19 firms are never financially constrained over the entire sample period, 8 firms are possibly financially constrained at some time, and 22 firms are likely financially constrained at some time.
} 


\subsection{Impulse Response to News on $Z_{t}$}

To illustrate the role of financial frictions as a transmission mechanism of TFP fluctuations, we explore the impulse responses of various macro aggregates to news shocks. We consider the following experiment: At period 0, the economy is at steady state. At the beginning of period 1, all agents receive unanticipated news that the aggregate technology $Z$ will increase by one percent in period 2. At the beginning of period 2, the technology improvement is materialized. Our choice of one period as the lag for technological changes to be realized is motivated by Beaudry and Portier (2006). ${ }^{25}$

Figure 1 plots the impulse response of capital reallocation and financial fictions of allocating capital, measured by the ratio of marginal productivity of capital between two types of projects. We see from Panel A that in response to the news shock, the gap of marginal product of capital decreases by about 3 percent and stays below the steady-state level throughout the boom period. This suggests that consistent with the empirical evidence, financial frictions in our model are countercyclical. Accordingly, when good news arrives, capital is reallocated from type- $l$ to type- $h$ projects. Panel B shows that the magnitude of capital reallocation on impact is about 2 percent of capital stock, a number that is reasonable according to sizes of capital reallocation reported by Eisfeldt and Rampini (2006).

\section{[Insert Figure 1]}

The efficiency gain on impact shows up as an increase in the aggregate TFP. This is evident from Figure 2, which illustrates the dynamics of aggregate TFP and its components following the news shock. Most importantly, the reallocation effect explains all of the increase in the aggregate TFP upon the arrival of the good news, reflecting the fact that, in our experiment, financial frictions on capital allocation are the only channel for triggering aggregate TFP fluctuations. After realization of the technology improvement, the technological effect starts to play a role, and the contribution of the reallocation effect to the aggregate TFP declines gradually. It is also noted that the gap of $M P K$ reverts slowly to the steady state, showing that the effects of variations in financial frictions are persistent (Figure 1). The resulting persistent reallocation effect amplifies TFP fluctuations at period 2 and afterwards, as shown in Figure 2.

\footnotetext{
${ }^{25}$ The evidence in Beaudry and Portier (2006) suggests that a permanent change in TFP may be associated with a up to 10 quarters long period during which there may be no actual change in technological opportunities. The results remain qualitatively the same if we assume that an anticipated shock is realized at period 3 . Our choice of one year as the lag for actual technological improvement to be materialized greatly eases the computation burden to solve for policy functions.
} 
[Insert Figure 2]

The increase of aggregate TFP makes the comovement of macro aggregates feasible. Figure 3 plots the impulse responses of macroeconomic variables. Although the contemporaneous technology remains unchanged, the arrival of good news generates an economic expansion immediately: consumption, investment and output all increase on impact. ${ }^{26}$ In other words, our model is capable of generating business cycles by establishing a source of TFP fluctuations.

[Insert Figure 3]

In summary, we show, in a simple model, the role of financial frictions as a transmission mechanism of TFP fluctuations through capital allocation: Endogenous variations of financial frictions in response to good news shocks can trigger a reallocation of capital; the redistribution of capital creates an efficiency gain as an increase of aggregate TFP. The increase in TFP allows macro aggregates to comove positively before the actual technology improvement is realized. ${ }^{27}$

\section{A Full-Blown Model}

The basic model of Section 2 has a number of limitations. By implicitly treating labor as a fixed factor, the production technology (2) implies a time-invariant labor allocation across projects. Prohibiting labor reallocation does not seem reasonable, given the importance of job creation and job destruction for U.S. business cycles. ${ }^{28}$ Moreover, the basic model is silent on the impulse response of labor supply and, hence, unable to address the issue of fluctuations in aggregate employment.

This section extends the basic model to overcome these limitations. There are two major changes. First, financial frictions are imposed on allocation of both capital and labor. Accordingly, labor will be reallocated along with capital following variations in financial frictions. Second, endogenous labor supply is introduced. In addition, we incorporate the following ingredients: investment adjustment costs; trend growth in technology and population; and heterogeneity in productive efficiency across different types of projects. We show that the main results of Section 2 are robust to these changes when the extended model (referred to as the

\footnotetext{
${ }^{26}$ The response of investment on impact is arguably small. We shall see a more reasonable contemporaneous response of investment in the next section, when investment adjustment costs are introduced.

${ }^{27}$ We also report business cycle statistics in Table A.1 of the Appendix. Although highly stylized, business cycle moments of the calibrated economy are close to those in the U.S. data, suggesting that our model can replicate the U.S. business cycles reasonably well.

${ }^{28}$ See, for example, Davis and Haltiwanger (1990), Caballero and Hammour (1994), and Caballero and Hammour (2005).
} 
"full-blown model" henceforth) is calibrated to U.S. data. Also, it performs well in replicating important business cycle moments.

\subsection{Projects}

As in the basic model of Section 2, projects are classified into two types: type- $h$ projects, constituting a fraction $\eta$ of all projects, which require working capital to be operative; and type-l projects, for which working capital is not necessary. We now introduce an additional dimension of heterogeneity across different types of projects: type- $h$ projects are associated with a different expected level of technology from that of type- $l$ projects. ${ }^{29}$

The production technology of a type- $i$ project, $i \in\{h, l\}$, is given by

$$
Y_{t}^{i}=A_{t}^{i}\left(\left(K_{t}^{i}\right)^{\alpha}\left(H_{t}^{i}\right)^{1-\alpha}\right)^{\mu}
$$

where $K_{t}^{i}$ and $H_{t}^{i}$ are capital and labor employed in a single type- $i$ project. $\mu<1$, implying decreasing returns to scale. ${ }^{30}$ The production technology (14) differs from (2) along two aspects. First, labor is introduced as inputs. Second, (14) allows technology $A_{t}^{i}$ to be different across projects. Specifically, $A_{t}^{i}$ contains three components.

$$
A_{t}^{i}=(1+g)^{t} \chi_{t}^{i} Z_{t}
$$

The first part, $(1+g)^{t}$, captures the trend of aggregate technology, where $g$ is the long-run growth rate of aggregate technology. The second and the third parts, $\chi_{t}^{i}$ and $Z_{t}$, respectively, refer to the project-specific technology and detrended aggregate technology.

We assume again that the magnitude of working capital for a type- $h$ project to be operative increases in the scale of production. Entrepreneurs of type- $h$ projects face the same limited enforcement problem of debt repayment as those in the model without labor. Similar to the model without labor, the incentive-compatibility condition imposes the following financial constraint

$$
D\left(K_{t}^{h}, H_{t}^{h}\right) \leq \theta V_{t+1}^{h}=\theta E_{t} \sum_{j=1}^{\infty} \hat{\beta}^{j} \pi_{t+j}^{h},
$$

\footnotetext{
${ }^{29}$ As surveyed by Bartelsman and Doms (2000), micro studies have consistently found that there is sizable dispersion in plant-level productivity within narrowly defined U.S. manufacturing industries. The ratio of average TFP for plants in the ninth decile of the productivity distribution relative to the average in the second decile was about 2 to 1 in 1972 and about 2.75 to 1 in 1987 . Moreover, more than one third of the plants remain in the same productivity quintile after five years (see Bartelsman and Dhrymes, 1998), indicating that productivity gaps among plants are quite persistent.

${ }^{30}$ The magnitude of $\mu$ captures the "span of control" of an entrepreneur, as mentioned by Lucas (1978). Basu and Fernald (1997) estimate returns to scale using data on 34 industries and find that, without correcting for aggregation, returns to scale appear strongly diminishing.
} 
where $D\left(K_{t}^{h}, H_{t}^{h}\right)$ stands for the divertible resource. At each period, the entrepreneur of a type- $h$ project chooses capital $K_{t}^{h}$ and labor $H_{t}^{h}$ to solve

$$
\max _{\left\{K_{t}^{h}, H_{t}^{h}\right\}} A_{t}^{h}\left(\left(K_{t}^{h}\right)^{\alpha}\left(H_{t}^{h}\right)^{1-\alpha}\right)^{\mu}-\left(r_{t}+\delta\right) K_{t}^{h}-w_{t} H_{t}^{h},
$$

subject to (16). The problem of an entrepreneur of the type-l project is

$$
\max _{\left\{K^{l}, H_{t}^{l}\right\}} A_{t}^{l}\left(\left(K_{t}^{l}\right)^{\alpha}\left(H_{t}^{l}\right)^{1-\alpha}\right)^{\mu}-\left(r_{t}+\delta\right) K_{t}^{l}-w_{t} H_{t}^{l}
$$

The first-order conditions of (17) and (18) imply the following allocation of capital between two types of projects.

$$
\begin{aligned}
& \alpha \mu A_{t}^{h}\left(K_{t}^{h}\right)^{\alpha \mu-1}\left(H_{t}^{h}\right)^{(1-\alpha) \mu}-\lambda_{t}^{h} D_{K_{t}^{h}} \\
= & \alpha \mu A_{t}^{l}\left(K_{t}^{l}\right)^{\alpha \mu-1}\left(H_{t}^{l}\right)^{(1-\alpha) \mu} \\
= & r_{t}+\delta,
\end{aligned}
$$

where $\lambda_{t}^{h}$ is the Lagrangian multiplier associated with the financial constraint (16). $D_{x}$ denotes the partial derivative of $D$ to variable $x$. Similarly, the allocation of labor follows

$$
\begin{aligned}
& (1-\alpha) \mu A_{t}^{h}\left(K_{t}^{h}\right)^{\alpha \mu}\left(H_{t}^{h}\right)^{(1-\alpha) \mu-1}-\lambda_{t}^{h} D_{H_{t}^{h}} \\
= & (1-\alpha) \mu A_{t}^{l}\left(K_{t}^{l}\right)^{\alpha \mu}\left(H_{t}^{l}\right)^{(1-\alpha) \mu-1} \\
= & w_{t} .
\end{aligned}
$$

Two remarks are in order. First, in the first-best allocation where the financial constraint is not binding $\left(\lambda_{t}^{h}=0\right)$, both types of projects have the same capital-labor ratio.

$$
\frac{K_{t}^{h}}{H_{t}^{h}}=\frac{K_{t}^{l}}{H_{t}^{l}}=\frac{\alpha w_{t}}{(1-\alpha)\left(r_{t}+\delta\right)} .
$$

Moreover, the first-best allocation of capital is determined by the relative production technology.

$$
\frac{K_{t}^{h}}{K_{t}^{l}}=\left(\frac{A_{t}^{h}}{A_{t}^{l}}\right)^{\frac{1}{1-\mu}} .
$$

Second, comparing the first-order condition in (19), it is immediate that news on an individual type- $h$ project's future technology $A_{t+j}^{h}$ can affect $K_{t}^{h}$ by changing the tightness of financial constraint in (16) and, therefore, $\lambda_{t}^{h}$. By contrast, news about $A_{t+j}^{l}$ has no direct impacts on $K_{t}^{l} .{ }^{31}$ We will use firm-level data to test this implication in Section 6.

\footnotetext{
${ }^{31}$ In our model, news about $A_{t+j}^{l}$ can affect $K_{t}^{l}$ indirectly via the general equilibrium effect since type- $l$ projects are homogeneous. The general equilibrium effect disappears if we consider $A_{t+j}^{l}$ as an idiosyncratic shock.
} 
Finally, we parameterize the divertible resource as

$$
D\left(K_{t}^{h}, H_{t}^{h}\right)=\left(\left(K_{t}^{h}\right)^{\alpha}\left(H_{t}^{h}\right)^{1-\alpha}\right)^{\mu}
$$

(23) is a natural extension of the specification (13). Moreover, (23) gives rise to the following property: Both types of projects have the same capital-labor ratio, a feature also in the firstbest allocation (21). The equality of the capital-labor ratio across projects shuts down the within-project resource misallocation (between capital and labor) as a potential source for efficiency gain and allows us to focus on the effect of resource reallocation across projects on aggregate productive efficiency.

\subsection{A Decomposition of TFP}

We assume that the labor income share is correctly measured, i.e., $(1-\alpha) \mu=1-\widehat{\alpha}$, where $1-\widehat{\alpha}$ stands for the aggregate labor income share. We then decompose the aggregate TFP as

$$
\begin{aligned}
\log T F P_{t} & =\log \frac{\sum_{i} A_{t}^{i}\left(\left(K_{t}^{i}\right)^{\alpha}\left(H_{t}^{i}\right)^{1-\alpha}\right)^{\mu}}{K_{t}^{\widehat{\alpha}} H_{t}^{1-\widehat{\alpha}}} \\
& =\log \frac{\sum_{i} A_{t}^{i}\left(K_{t}^{i} / H_{t}^{i}\right)^{(\alpha-1) \mu}\left(K_{t}^{i}\right)^{\mu}}{\left(K_{t} / H_{t}\right)^{\widehat{\alpha}-1} K_{t}} \\
& =\underbrace{(\mu-1) \log K_{t}}_{\text {the level effect }}+\underbrace{\log \sum_{i} A_{t}^{i}\left(\frac{K_{t}^{i}}{K_{t}}\right)^{\mu}}_{\text {adjusted Solow residual }} .
\end{aligned}
$$

The first term on the RHS of (24) is a level effect: Given decreasing returns to scale, larger scales reduce aggregate productivity. The second term is the sum of the project-specific technology weighted by the share of capital in each type of project, referred to as "adjusted Solow Residual." Accordingly, the percentage deviation of aggregate TFP from its balanced growth path can be decomposed as

$$
\begin{aligned}
\triangle \log T F P_{t} & =\triangle \log \left(\frac{\eta A_{t}^{h}\left(K_{t}^{h}\right)^{\mu}+(1-\eta) A_{t}^{l}\left(K_{t}^{l}\right)^{\mu}}{K_{t}}\right) \\
& =(\mu-1) \triangle \log K_{t}+\triangle \log \left(\eta A_{t}^{h}\left(\frac{K_{t}^{h}}{K_{t}}\right)^{\mu}+(1-\eta) A_{t}^{l}\left(\frac{K_{t}^{l}}{K_{t}}\right)^{\mu}\right)
\end{aligned}
$$


where the percentage change of "adjusted Solow Residual" can be further decomposed as

$$
\begin{aligned}
& \triangle \log \left(\eta A_{t}^{h}\left(\frac{K_{t}^{h}}{K_{t}}\right)^{\mu}+(1-\eta) A_{t}^{l}\left(\frac{K_{t}^{l}}{K_{t}}\right)^{\mu}\right) \\
= & \underbrace{\left.\triangle \log \left(\eta A_{t}^{h}\left(\frac{K_{t}^{h}}{K_{t}}\right)^{\mu}+(1-\eta) A_{t}^{l}\left(\frac{K_{t}^{l}}{K_{t}}\right)^{\mu}\right)\right|_{\frac{K_{t}^{i}}{K_{t}}=\frac{\bar{K}^{i}}{\bar{K}}}}_{\text {the technological effect }} \\
& +\underbrace{\left.\triangle \log \left(\eta A_{t}^{h}\left(\frac{K_{t}^{h}}{K_{t}}\right)^{\mu}+(1-\eta) A_{t}^{l}\left(\frac{K_{t}^{l}}{K_{t}}\right)^{\mu}\right)\right|_{A_{t}^{i}=\bar{A}^{i}}}_{\text {the reallocation effect }} \\
& + \text { cross product term. }
\end{aligned}
$$

The first and second arguments on the RHS of (26) are the "technological effect" and the "reallocation effect," which bear meanings similar to those of their counterparts in the economy without labor. Again, in order to highlight the reallocation effect, we specify primitive shocks as news shocks on future technology (either aggregate or project-specific, as described in more detail in Section 5.1.2). As a result, changes in "adjusted Solow Residual" are driven purely by the reallocation effect before the technology change is materialized.

\subsection{Household Sector}

We incorporate investment adjustment costs and trend growth in population into the household problem, as often adopted in the literature. There is a stand-in household with $N_{t}$ working-age members at date $t$. The size of the household evolves over time exogenously at a constant rate $n=N_{t} / N_{t-1}-1$. In this framework, the representative household's problem solves

$$
\max _{\left\{c_{t}, h_{t}, k_{t+1}\right\}_{t=0}^{\infty}} E_{0}\left[\sum_{t=0}^{\infty} \beta^{t} N_{t} u\left(c_{t}, h_{t}\right)\right],
$$

subject to

$$
\begin{aligned}
C_{t}+G\left(I_{t}, K_{t}\right) & =\left(r_{t}+\delta\right) K_{t}+w_{t} H_{t}+(1-\eta) \pi_{t}^{l}+\eta \pi_{t}^{h}, \\
K_{t+1} & =(1-\delta) K_{t}+I_{t}, \\
G\left(I_{t}, K_{t}\right) & =I_{t}+\kappa\left(\frac{I_{t}}{K_{t}}-\delta-n-g_{y}\right)^{2} K_{t} .
\end{aligned}
$$

where $c_{t} \equiv C_{t} / N_{t}$ is per member consumption, $h_{t} \equiv H_{t} / N_{t}$ is the fraction of hours worked per member of the household. $I_{t}$ stands for investment and $\kappa$ is the coefficient of investment adjustment costs. The role of investment adjustment costs (29) will be discussed in Section 5.3.1. $g_{y}$ is the growth rate of output per capita at the balanced growth path, which follows

$$
1+g_{y}=(1+g)^{\frac{1}{1-\alpha \mu}}(1+n)^{\frac{\mu-1}{1-\alpha \mu}} .
$$


The first-order conditions imply the following standard equations

$$
\begin{aligned}
u_{c}\left(c_{t}, h_{t}\right) w_{t} & =-u_{h}\left(c_{t}, h_{t}\right), \\
q_{t} & =1+2 \kappa\left(\frac{I_{t}}{K_{t}}-\delta-n-g_{y}\right), \\
q_{t} u_{c}\left(c_{t}, h_{t}\right) & =\beta E_{t}\left[u_{c}\left(c_{t+1}, h_{t+1}\right)\left(\begin{array}{c}
r_{t}+\delta+2 \kappa\left(\frac{I_{t}}{K_{t}}-\delta-n-g_{y}\right) \frac{I_{t}}{K_{t}} \\
-\kappa\left(\frac{I_{t}}{K_{t}}-\delta-n-g_{y}\right)^{2}+q_{t+1}(1-\delta)
\end{array}\right)\right],
\end{aligned}
$$

where $q_{t}$ is the marginal $q$, and $u_{x}\left(c_{t}, h_{t}\right)$ is the marginal utility (or disutility) associated with variable $x, x=c$ or $h$. Equation (30) is the first-order condition for labor. Equation (31) is the first-order condition for investment, and Equation (32) is the standard Euler equation with quadratic adjustment costs.

Finally, we keep the timing and information structures the same as those in the economy without labor.

\subsection{Competitive Equilibrium}

A competitive equilibrium of this economy consists of an allocation $\left\{C_{t}, H_{t}, K_{t+1}\right\}_{t=0}^{\infty}$ for the representative household, allocation $\left\{K_{t}^{h}, H_{t}^{h}, K_{t}^{l}, H_{t}^{l}\right\}_{t=0}^{\infty}$ for entrepreneurs and price system $\left\{w_{t}, r_{t}\right\}$ such that

- Given prices, the allocation $\left\{C_{t}, H_{t}, K_{t+1}\right\}_{t=0}^{\infty}$ solves the household's problem (27).

- Given prices, the allocation $\left\{K_{t}^{h}, H_{t}^{h}, K_{t}^{l}, H_{t}^{l}\right\}_{t=0}^{\infty}$ solves the entrepreneur's profit maximization problems (17) and (18).

- Capital market clears: $\eta K_{t}^{h}+(1-\eta) K_{t}^{l}=K_{t}$.

- Labor market clears: $\eta H_{t}^{h}+(1-\eta) H_{t}^{l}=H_{t}$.

- Good market clears:

$$
C_{t}+G\left(I_{t}, K_{t}\right)=Y_{t} \equiv \eta A_{t}^{h}\left(\left(K_{t}^{h}\right)^{\alpha}\left(H_{t}^{h}\right)^{1-\alpha}\right)^{\mu}+(1-\eta) A_{t}^{l}\left(\left(K_{t}^{l}\right)^{\alpha}\left(H_{t}^{l}\right)^{1-\alpha}\right)^{\mu} .
$$

For numerical simulation, we also define the recursive competitive equilibrium in Section 8.2 of the Appendix. We solve for decision rules by policy function iterations. 


\section{Calibration}

In this section, we calibrate the full-blown model using data from the 2005 revision of National Income and Product Accounts (NIPA) to match the average values of U.S. data over the 19602004 period. Our measure of capital stock includes government capital and stock of consumer durables, following Cooley and Prescott (1995). Again, one period in the model corresponds to one calendar year.

\subsection{Preference}

We let the period utility of the household follow the utility specification in Greenwood, Hercowitz and Hoffman (1988, "GHH" henceforth).

$$
u\left(c_{t}, h_{t}\right)=\frac{\left(c_{t}-\psi \Gamma_{t} \frac{h_{t}^{1+\nu}}{1+\nu}\right)^{1-\sigma}-1}{1-\sigma}
$$

where $\Gamma_{t}=\left(1+g_{y}\right)^{t}$ is incorporated in the utility to ensure the stationarity of hours on the balanced growth path. Under GHH preference, the income effect on labor supply is shut down, and the only channel for shocks to affect labor supply is the substitution effect of changes in wage rates. ${ }^{32}$

We set $\nu$ to 0.4 to match a Frisch elasticity of 2.5. ${ }^{33}$ The parameter $\psi$ is set to 1.5 so that the hours worked is 0.31 at the steady state. The discount factor $\beta$ is set to 0.979 , implying a steady state real interest rate of 4 percent. The population growth rate $n$ is set to 0.0147 , which is the average growth rate of the civilian non-institutional population aged 16 over between 1960 and 2004.

\subsection{Technology}

We set $g_{y}=0.0183$, which is consistent with the long-run average growth rate of U.S. real GNP per capita. We set $\mu$ to 0.85 , the value used by Atkeson and Kehoe (2001). The parameter $\alpha$ is then set so that the labor income share is 0.6 . This yields a value of $\alpha$ of 0.294 . The depreciation rate $\delta$ is set to match an investment capital ratio of 0.074 , the average between 1960 and 2004. This gives $\delta=0.04$. The adjustment cost parameter, $\kappa$, is set to 2.0, which is close to the estimated result of Gilchrist and Himmelberg (1995).

\footnotetext{
${ }^{32}$ Greenwood et al. (1988) show that, ceterus paribus, models that adopt this type of preference can generate hours volatility over the business cycles closer to the U.S. data than models using the preference that were described in King, Plosser and Rebelo (1998).

${ }^{33}$ A Frisch elasticity of 2.5 reflects both the intensive and extensive margins of aggregate labor supply.
} 
As a baseline case, we keep the level of project-specific technology $\chi_{t}^{i}$ constant over time and equal to $\chi^{i}$. The specification for news shocks on aggregate technology is the same as that in (9). We normalize the type- $l$ project-specific technology $\chi^{l}$ to 1 . To calibrate $\eta, \chi^{h}$, the type- $h$ project-specific technology and $\theta$, the pledgeable share of future project value, we exploit the fact that on the balanced growth path,

$$
\theta \chi^{h}=\frac{\frac{1}{\widehat{\beta}\left(1+g_{y}\right)}-1}{1-\mu /\left(\frac{\bar{Y}^{h} / \bar{H}^{h}}{\bar{Y}^{l} / \bar{H}^{l}}\right)},
$$

where variables with upper bars denote the steady-state values of their detrended counterparts. ${ }^{34}$ Since both the capital-output ratio and the ratio of labor productivity of two types of projects are closely related to $\chi^{h}$ and $\theta$, we can calibrate the values of $\eta, \chi^{h}$ and $\theta$ simultaneously to match two targets: an empirical ratio of labor productivity of 2 between the 25 th and the 75 th percentile producers and an aggregate capital-output ratio of $2.5 .{ }^{35}$ Note that there is an identification problem, in the sense that we need to choose three parameter values to match two ratios. Since in our model there are only two types of projects, we let $\eta=0.5$ so that the median of type- $h$ and type- $l$ projects corresponds to the 75 th- and 25 th-percentile producers, respectively. ${ }^{36}$ Accordingly, $\chi^{h}=1.69$ and $\theta=0.10 .{ }^{37}$ The value of $\chi^{h}$ implies a value of 0.26 for the standard deviation of $\log \chi^{i}$, which is well within the range estimated in the literature. ${ }^{38}$ Our sensitivity analysis in Section 5.3.1 shows that the following quantitative results are essentially unchanged with $\eta=0.25$, and $\chi^{h}$ and $\theta$ recalibrated to match the same moments.

For all other parameters, the calibration follows the same procedure as in the economy without labor. Table 2 summarizes the calibrated parameters.

\footnotetext{
${ }^{34}$ We detrend each aggregate variable except hours input by dividing it by $\left(\left(1+g_{y}\right)(1+n)\right)^{t}$. Aggregate hours are detrended by $(1+n)^{t}$. Equation (34) is obtained by computing the steady state value of the ratio of marginal product of capital, which is equivalent to the ratio of labor productivity in our model.

${ }^{35}$ According to Bartelsman and Doms (2001) and Table 1 in Syverson (2004), the average ratio of the labor productivity of the 25 th-percentile producers to the 75 th-percentile producers is about 2 .

${ }^{36}$ Recall that our choice of $\eta=0.5$ is motivated by the evidence in Kaplan and Zingales (1997).

${ }^{37} \mathrm{~A}$ higher expected level of technology for type- $h$ projects is consistent with the empirical findings. For instance, Carpenter and Peterson (2002) find that many small high-tech firms in the Compustat database obtain little debt financing. Accordingly, Opler, Pinkowitz, Stulz and Williamson (1999) find that firms with stronger growth opportunities and higher R\&D expenses, as measured by a high market to book ratio and $\mathrm{R} \& \mathrm{D}$ to sales ratio, have larger cash holdings, suggesting that they are more likely to be credit-constrained.

${ }^{38}$ Cooper and Haltiwanger (2006) specified a log AR(1) process for the plant-specific shock and obtained a value of 0.64 for the estimated standard deviation.
} 
Table 2. Parameter Values For the Full-Blown Economy

\begin{tabular}{clc}
\hline \hline Symbol & \multicolumn{1}{c}{ Definition } & Value \\
\hline$n$ & \multicolumn{1}{c}{ Population growth rate } \\
& \multicolumn{1}{c}{ Technology } & 0.015 \\
$\alpha$ & Capital share in production function & 0.294 \\
$g_{y}$ & Growth rate of output per capita & 0.018 \\
$\phi$ & Entrepreneurial survival rate & 0.90 \\
$\delta$ & Depreciation rate for capital & 0.04 \\
$\chi^{h}$ & Expected type- $h$ project-specific technology & 1.69 \\
$\mu$ & Production parameter & 0.85 \\
$\rho$ & Autocorrelation coefficient & 0.95 \\
$\sigma_{\epsilon}^{Z}$ & Standard deviation of information innovation & 0.013 \\
$\kappa$ & Adjustment cost parameter & 2.0 \\
& $\quad$ Preference & \\
$\beta$ & Discount factor in utility function & 0.979 \\
$\psi$ & Disutility parameter for leisure & 1.6 \\
$\sigma$ & Coefficient of relative risk aversion & 1 \\
$\nu$ & Inverse of Frisch elasticity & 0.4 \\
& & Market \\
$\theta$ & Default parameter & 0.10 \\
$\eta$ & Fraction of high-tech projects & 0.50 \\
\hline
\end{tabular}

\section{Results}

In this section, we first plot impulse responses of macro aggregates to news shocks on future technology improvements. We then report the business cycle statistics. Finally, we quantify the importance of our model mechanism for TFP fluctuations.

\subsection{Impulse Responses to News}

The experiments for impulse responses are similar to those in the economy without labor. As a baseline case, the economy is subject to news shocks on aggregate technological improvement. Later, we also report impulse responses to news shocks on technological improvement specific to type- $h$ projects. That experiment might help us to understand the role of financial frictions on capital allocation when there are good prospects on future profitability that are specific to some high-tech industries, such as the IT industry in the late 1990s.

\subsubsection{Impulse Response to News on the Aggregate Technology $Z_{t}$}

Figure 4 depicts the response of capital reallocation, together with financial fictions of allocating capital, measured by the ratio of marginal productivity of capital between two types of projects. 
We see from panel A that in response to the news shocks, the ratio decreases by about 0.4 percent and stays below the steady-state level throughout the boom period. This suggests that the countercyclical feature of financial frictions on capital allocation still prevails when endogenous labor supply and reallocation are allowed for. The magnitude of capital reallocation on impact, as plotted in panel $\mathrm{B}$, is 1.0 percent of capital stock.

\section{[Insert Figure 4]}

The reduction of financial frictions on capital allocation results in an increase in aggregate productive efficiency. This is evident from Figures 5 and 6 , which plot the response of aggregate TFP and its components to the good news. The initial response of TFP amounts to 0.36 percent, which is roughly one third of the magnitude of the TFP increase when technology improvement is realized. ${ }^{39}$ Such a magnitude is quantitatively in line with the empirical findings of Beaudry and Portier (Figure 1, 2006), who use structural VAR models to estimate the responses of TFP to a news shock. The decomposition in Figure 6 shows that reallocation effects explain all the increase in TFP before the technology improvement is materialized. Moreover, as in the benchmark model, the transmission mechanism in our model economy is capable of amplifying the effects of technological shocks. Figure 4 shows that variations in financial frictions have persistent effects; the gap of $M P K$ reverts gradually to the steady state. The corresponding reallocation effect, therefore, also serves as an amplification mechanism by contributing to TFP fluctuations at period 2 and afterwards, as illustrated by Figure 6 .

\section{[Insert Figure 5, 6 and 7]}

The increase in aggregate TFP on impact leads to comovement of macro aggregates, as can be seen in Figure 7. Though the exogenous technology improvement materializes at period 2, the economy starts to boom at period 1. Consumption, investment, output and hours worked all increase on impact. As one can see from the first two columns of Table 3, the effects of such a news shock are sizable for most variables except hours worked: output, consumption and investment increase by 0.43 percent, 0.45 percent and 0.35 percent, respectively. In short, similar to the model without labor, the increase in TFP arising from resource allocation in our full-blown model also generates business cycles.

\footnotetext{
${ }^{39}$ Figure 5 also shows that the level effect plays a minor role in the change of aggregate TFP, especially during the initial periods.
} 
Table 3. Responses to News on Aggregate Technology and Project-Specific Technology

\begin{tabular}{lcccc}
\hline \hline & \multicolumn{2}{c}{$Z$} & \multicolumn{2}{c}{$A^{h}$} \\
\cline { 2 - 5 } & $t=1$ & $t=2$ & $t=1$ & $t=2$ \\
\hline$Y$ & 0.43 & 2.01 & 0.59 & 0.97 \\
$C$ & 0.45 & 1.73 & 0.70 & 0.90 \\
$I$ & 0.35 & 3.36 & 0.13 & 1.29 \\
$H$ & 0.13 & 1.33 & 0.18 & 0.17 \\
$T F P$ & 0.36 & 1.20 & 0.49 & 0.86 \\
\hline
\end{tabular}

Note: Numbers in the table are the percentage deviation from the steady-state value. Parameter values are in Table 2.

\subsubsection{Impulse Response to News on the Type- $h$ Technology $\chi_{t}^{h}$}

The U.S. boom in the 1990s was fueled largely by the optimism of a "New Economy," represented by technological breakthroughs in the computer sector and their wide usage in other sectors. Therefore, it is natural to think of one candidate for primitive shocks as news on future advances of technology in the high-tech industry.

Therefore, we consider news shocks on type- $h$ project-specific technology. Specifically, we let $Z_{t}$ and $\chi_{t}^{l}$ remain constant (equal to their mean) and assume that

$$
\log \chi_{t+1}^{h}=(1-\rho) \log \bar{\chi}^{h}+\rho \log \chi_{t}^{h}+\epsilon_{t}^{\chi^{h}}
$$

where $\epsilon_{t}^{\chi^{h}}$ denotes information innovation on the next-period technology, $\chi_{t+1}^{h}$. Here, again, we assume that news shocks in the current period are uncorrelated with current technology $\chi_{t}^{h}$; rather, it is a perfect signal on the future technology innovation observed by all agents in this economy.

To compare the results from shocks on aggregate and project-specific technology, we keep the same parameterization as in Table 3, except for the variance of information innovations, denoted by $\sigma_{\epsilon}^{\chi^{h}}$. We choose the value of $\sigma_{\epsilon}^{\chi^{h}}$ such that the standard deviation of the log of H-P detrended TFP simulated from the model is equal to the corresponding value in annual U.S. data. The calibration gives $\sigma_{\epsilon}^{\chi^{h}}=2.24 \%$.

The experiment is similar to the previous one: at period 0 , the economy is at the steady state. At the beginning of period 1, all agents receive unanticipated news that $\chi_{t}^{h}$ will increase by one percent at period 2. At the beginning of period 2, the technology improvement is materialized.

Although the dynamics are qualitatively similar, with news shocks on $\chi^{h}$, their effects are quantitatively larger compared to the baseline case. ${ }^{40}$ In particular, the initial response of

\footnotetext{
${ }^{40}$ We suppress figures of impulse response functions due to their similarity to Figures 4 to 7.
} 
aggregate TFP becomes considerably larger. It increases by nearly 0.50 percent, more than half of the increase in aggregate TFP when the technology improvement is realized (Table 3). Again, the large response of aggregate TFP on impact is purely due to the reallocation effect. The intuition for stronger effects of news shocks on the project-specific technology is as follows. Given $\chi^{l}$ unchanged, capital demanded by type- $h$ projects will be rented at a relatively cheaper price than with news shocks to aggregate technology. This implies a larger increase in future profit for type- $h$ projects. A higher project value, accordingly, relaxes the financial constraint by a larger extent and induces more resource to flow from type- $l$ to type- $h$ projects. Financial frictions on capital allocation, measured by the gap in marginal productivity of capital, reduce more sharply by 0.57 percent on impact. Capital reallocation in response to news shocks to $\chi^{h}$ (with a size of 1.43 percent), accordingly, turns out to be more active than its counterpart to news shocks on $Z$ (with a size of 1.05 percent). Finally, the initial response of macroeconomic variables is also remarkable. The news drives the initial aggregate output by 0.59 percent, more than half of the output increase when the technological improvement is realized at period 2 (see, also, the third and fourth columns of Table 3).

\subsection{Business Cycle Statistics}

We have shown the role of financial frictions on capital allocation as a transmission mechanism of aggregate TFP fluctuations. Moreover, the resulting aggregate TFP fluctuation leads to business cycles by allowing positive comovement of macro aggregates. In this subsection, we explore how our model performs in other dimensions of business cycles. We compare business cycle moments in the U.S. data with those simulated from the calibrated model with two different specifications for news shocks, (9) and (35). To simulate the economy, we first use the quadrature method described in Tauchen and Hussey (1991) to construct a nine-state Markov chain that approximates news shock processes (9) and (35), respectively. We then simulate the economy 1000 times, each containing 45 periods, as our data span for 45 years. Then, both artificial and actual U.S. data are H-P filtered with a weight of 100 . We use their cyclical components to compute the business cycle statistics for both data series. Table 4 reports the sample mean of the standard deviation of macro variables. 
Table 4. Volatility of Macro Variables

\begin{tabular}{|c|c|c|c|}
\hline & \multirow[t]{2}{*}{ Data } & \multicolumn{2}{|c|}{ Model Specifications } \\
\hline & & News to $Z$ & News to $\chi^{h}$ \\
\hline Used for calibration & & & \\
\hline the standard deviation of TFP & 0.0125 & 0.0123 & 0.0127 \\
\hline Not used for calibration & & & \\
\hline the standard deviation of output & 0.0173 & 0.0212 & 0.0131 \\
\hline the standard deviation of consumption & 0.0120 & 0.0176 & 0.0118 \\
\hline the standard deviation of investment & 0.0597 & 0.0378 & 0.0233 \\
\hline the standard deviation of hours & 0.0154 & 0.0151 & 0.0024 \\
\hline
\end{tabular}

We first examine the results in the baseline case of news shocks to $Z$, the aggregate technology. Volatility of macro aggregates is reported in the middle column of Table 4 . Note that the standard deviation of simulated output is equal to 2.12 percent, larger than the corresponding value in the U.S. data (1.73 percent). By contrast, output data simulated from standard RBC models are less volatile than the U.S. data. This suggests that the presence of financial frictions amplifies business cycle fluctuations, as pointed out by Carlstrom and Fuerst (1997), among many others. The simulated volatilities of consumption and investment have the standard ordering: consumption is less volatile and investment is more volatile relative to output. The volatility of hours implied by the model is almost the same as in the data. To sum up, business cycle moments of the calibrated economy are close to those in the U.S. data, suggesting that our model can replicate U.S. business cycles reasonably well.

The results in the case of news shocks to $\chi^{h}$ are given in the right column of Table 4 . Not surprisingly, the volatilities fall sharply, since type- $l$ projects are immune to news shocks. The decline in the volatility of hours is the most remarkable. Recall that the wage rate is determined by the marginal labor productivity of type-l projects (see equation 20). The constancy of project-specific technology $\chi^{l}$ thus implies a rather stable wage rate and labor supply over business cycles.

The cross-correlation statistics is reported in Table A-2 in the Appendix. The main feature is that under both types of news shocks, all macro variables are highly procyclical, consistent with the stylized fact of U.S. business cycles. With only one shock, our model, like standard $\mathrm{RBC}$ models, tends to overestimate contemporaneous correlation coefficients.

\subsection{Quantifying the Importance of the Model Mechanism}

We further examine the quantitative importance of the above mechanism for TFP fluctuations over U.S. business cycles. As mentioned in the introduction, TFP fluctuations play a central 
role in U.S. business cycles. This feature is well captured by our model, as well as by previous business cycle models, though our primitive shocks are fundamentally different. In our calibrated models, news about future improvement in $Z$ or $\chi^{h}$ causes a reduction in financial frictions on capital allocations. This results in an increase in aggregate TFP, which leads to news-driven business cycles (NDBC henceforth) featuring comovement of output, consumption, investment and hours simultaneously. By contrast, without the efficiency gain from the endogenous variation of financial frictions, news shocks, which are unrelated to the current technology, can hardly lead to an economic expansion: Consumption and investment or hours will comove negatively due to the tension between the income and the substitution effects of news shocks. ${ }^{41}$ A positive comovement of macro aggregates is a stylized fact of business cycles. Therefore, in this section, we take two approaches to examining the relevance of the mechanism illustrated here for TFP fluctuations over U.S. business cycles. First, we check the robustness of our model on the positive comovement of macro aggregates under different parameterization. Second, we show analytically that variations in frictions on new capital investment cannot generate comovement of macro aggregates.

\subsubsection{Robustness Check for News-Driven Business Cycles}

We first check the robustness of our comovement result for two parameters: the adjustment cost coefficient $\kappa$ and the inverse of intertemporal elasticity of substitution $\sigma$. The magnitude of these two parameters governs the trade-off between current consumption and investment. ${ }^{42}$ The possible ranges of parameter values that can generate NDBC are given in Table 5 .

Table 5. Ranges of Parameter Values that Generate NDBC

\begin{tabular}{lcc}
\hline \hline & $\kappa$ & $\sigma$ \\
\cline { 2 - 3 } News Shock to $Z$ & $(0.13, \infty)$ & $(0.11,1.48)$ \\
News Shock to $\chi^{h}$ & $(0, \infty)$ & $(0,2.95)$ \\
\hline
\end{tabular}

For a news shock to $Z$, the adjustment cost coefficient $\kappa$ has to be larger than 0.13 , which is lower than the lowest estimate of 0.20 in the literature (see Cooper and Haltiwanger, 2006).

\footnotetext{
${ }^{41}$ In standard RBC models, anticipation of future technological improvement will increase current consumption and reduce investment through the income effect. On the other hand, a higher rate of return for investment will tend to increase investment and postpone consumption via the substitution effect. The relative importance of these two effects depends on the intertemporal elasticity of substitution. Moreover, good news will reduce the labor supply through a negative income effect, because the orthogonality of news shocks to current technology causes no substitution effect.

${ }^{42}$ The value of Frisch elasticity $\nu$ determines the magnitude of labor supply response. However, our comovement result holds for the whole domain of $\nu$, as the GHH preference has shut down the income effect on labor supply.
} 
Note that adjustment costs cannot help to generate comovement of macro aggregates in standard neoclassical models, as shown by Beaudry and Portier (2007). By contrast, introducing adjustment costs in the present model helps investment to comove with output and consumption. To see this, consider a news shock that predicts future technological improvement. If $\sigma$, the inverse of intertemporal elasticity of substitution, were very large, agents would increase consumption substantially for consumption smoothing, resulting in a decline in investment. However, this would not occur with sufficiently large adjustment costs since, otherwise, agents would have to pay large adjustment costs to increase investment when the technological improvement materializes.

To have the comovement of consumption and investment, $\sigma$ has to fall into the range of $(0.11,1.48)$ under the benchmark parameterization. If $\sigma$ is too small, consumption will decline in the first period due to the very large intertemporal elasticity of substitution. On the other hand, if $\sigma$ is too large, the desire for consumption smoothing is too strong, resulting in a large initial response of consumption to news shocks, which forces investment to decline. This also implies that larger capital adjustment costs tend to relax the upper bound of $\sigma$. In fact, if we increase the adjustment cost coefficient to 5 , a value within the range estimated by the literature (see Cooper and Haltiwanger, 2006), the upper bound of $\sigma$ increases to 1.91.

The conditions for comovement are substantially relaxed when news shocks are projectspecific. Under benchmark parameterization, business cycles can be triggered by expectations in an economy without capital adjustment costs. The upper bound of $\sigma$ also increases to 2.95. This is because, with project-specific news shocks, the response of aggregate TFP on impact is quantitatively larger, making the tension between the income and substitution effect of news shocks less severe.

We next check the robustness of our quantitative results for $\eta$, the share of constrained firms. Although the parameterization of $\eta$ in the benchmark case can be motivated from the empirical study of Kaplan and Zingales (1997), it is worth assessing the extent to which the choice of $\eta$ may change the results. To this end, we reduce the share of constrained firms by half so that $\eta=0.25$. Our targets are the same as in our benchmark model: an empirical ratio of labor productivity of 2 between the 25 th- and the 75 th-percentile producers and an aggregate capital-output ratio of 2.5. Since firm-specific productivity is homogeneous within each type of entrepreneur in our model, $\eta=0.25$ can be seen as a lower bound for the fraction of constrained firms in order to match the labor productivity ratio between the 25 th- and the 75th-percentile producers. Accordingly, $\chi^{h}=2.0$ and $\theta=0.086 .{ }^{43}$

\footnotetext{
${ }^{43}$ We also recalibrate $\psi=1.72$ to match hours worker to be 0.31 at the steady state.
} 
The first two columns of Table 6 report the impulse responses of macro aggregates to a onepercent positive news shock on $Z$. The impulse responses to a one-percent positive news shock on $A^{h}$ are given in the third and fourth columns. Interestingly, the results are essentially the same as those in Table 3. The reason for the similarity of impulse responses under different $\eta$ is as follows. A smaller share of financially constrained firms tends to reduce the total amount of capital reallocated from type- $l$ to type- $h$ projects and, thus, the aggregate efficiency gain from reallocation, as shown by the reallocation effect in equation (26). On the other hand, it also tends to increase the capital-output ratio at the aggregate level. To maintain the aggregate capital-output ratio, an increase in $\chi^{h}$ is required. ${ }^{44} \mathrm{~A}$ higher $\chi^{h}$ facilitates more capital to be reallocated from type- $l$ to type- $h$ projects and, therefore, tends to increase the aggregate efficiency gains. Our simulation indicates that the negative effect of a small $\eta$ and the positive effect of a large $\chi^{h}$ on the reallocation effect in equation (26) are quantitatively similar under our calibration strategy and, therefore, create no major changes to our results. Overall, the above robustness checks indicate that the mechanism described in this paper may well be quantitatively important for TFP fluctuations over U.S. business cycles.

Table 6. Responses to News on Aggregate Technology and Project-Specific Technology

\begin{tabular}{lcccc}
\multicolumn{4}{c}{$(\eta=0.25)$} \\
\cline { 2 - 5 } & $t=1$ & $t=2$ & $t=1$ & $t=2$ \\
\hline$Y$ & 0.44 & 2.02 & 0.60 & 0.99 \\
$C$ & 0.46 & 1.74 & 0.71 & 0.91 \\
$I$ & 0.36 & 3.27 & 0.13 & 1.31 \\
$H$ & 0.13 & 1.33 & 0.18 & 0.18 \\
$T F P$ & 0.36 & 1.20 & 0.49 & 0.88 \\
\hline
\end{tabular}

Note: Numbers in the table are the percentage deviation from the steady state value. $\eta=0.25$,

$$
\chi^{h}=2.0, \theta=0.086 \text { and } \psi=1.72 \text {. All other parameter values are in Table } 2 .
$$

\subsubsection{Non-existence of NDBC with Frictions on New Capital Investment}

Note that there may exist other channels for financial frictions to affect aggregate productive efficiency. For example, Kiyotaki and Moore (1997) construct a model in which financial frictions are imposed on new investment, instead of on capital allocation. Which mechanism is empirically more relevant for driving TFP fluctuations over business cycles? In Section of 8.3 in the Appendix, we show analytically that in two-sector models with financial frictions on the new investment goods sector, consumption, hours and investment must comove negatively upon

\footnotetext{
${ }^{44}$ Accordingly, a lower $\theta$ is needed to maintain the ratio of labor productivity of two types of projects, as indicated by equation (34) .
} 
news shocks. The intuition is as follows. Variations of frictions on new investment in response to primitive shocks cannot affect productive efficiency on impact. Moreover, a relaxation of the financial constraint induces capital and labor to shift from the consumption good to the investment good sector. As a result, consumption and investment move in opposite directions.

Such a negative correlation is at odds with the stylized facts of business cycles. Accordingly, it casts doubt on the empirical relevancy of frictions in the investment good sectors as a source of TFP fluctuations. In our model, by contrast, relaxing the financial constraint can trigger an immediate expansion of TFP by reallocating existing resources. This makes the positive comovement of macro aggregates feasible. We now turn to the U.S. data to directly test our theory.

\section{Empirical Evidence}

So far, we have constructed a theory in which financial frictions on capital allocation serve as a transmission mechanism of TFP fluctuations. To what extent is our proposed mechanism empirically relevant for aggregate TFP fluctuations? An answer to this question relies on two sub-questions. First, to what extent do resource reallocations contribute to aggregate productivity fluctuations? Given its quantitative importance, the next question is whether primitive shocks can lead to countercyclical variations in financial frictions and, therefore, resource reallocation over the business cycles.

The evidence from Basu and Fernald (2000) provides strong support for the importance of reallocation for aggregate productivity fluctuations over business cycles. Specifically, they decompose aggregate Solow residuals into four components: (i) procyclical technology shock; (ii) widespread imperfect competition and increasing returns; (iii) variable utilization of input over the cycle; and (iv) resource reallocation. The reallocation effect reflects changes in an economy's ability to produce goods and services for final consumption from given primary inputs of capital and labor. Using industry-level data compiled by Dale Jorgenson and Barbara Fraumeni, Basu and Fernald find that when subtracting the estimated reallocation terms from Solow residuals, the correlation between Solow residuals and output fell to about zero. This indicates that reallocation over the business cycle is key to understanding aggregate productivity fluctuations.

Regarding the second question, our theory suggests a role for news shocks to cause variations in financial frictions, which trigger capital reallocation and aggregate TFP fluctuations. The theory delivers two testable implications regarding the transmission mechanism. First, financial frictions on capital allocation are countercyclical. This implies that financially constrained 
firms acquire more capital in boom than unconstrained firms do, while the opposite is true in recession. Second, the key reason for frictions on capital allocation to be countercyclical is that prospects on an individual firm's future profitability affect financially constrained firms' capital acquisition, but not unconstrained firms'. In other words, the presence of financial constraint allows changes in the firm-level forecast of future profitability to affect current capital allocation. ${ }^{45}$ The rest of the section aims to test both implications using firm-level data.

\subsection{Data}

One of the major difficulties of the test is how to distinguish firms that are financially constrained from those that are not. We use an index constructed by Lamont, Polk and SaaRequejo (2001), which is based on Kaplan and Zingales (1997), to measure the likelihood of a firm being financial constrained. We denote the index as $K Z$.

$K Z$ is a weighted average of a firm-year's cash flow, cash dividends, cash balances, leverage and firm's average $Q$, with negative weights on the first three and positive ones on the last two. These weights are obtained by estimation of ordered logit models of the probability that a firm falls in one of the five categories: (1) not financially constrained; (2) likely not to be financially constrained; (3) difficult to classify as either constrained or not; (4) likely to be financially constrained; (5) undoubtedly to be financially constrained. ${ }^{46}$ A higher $K Z$, therefore, implies a higher possibility of being financially constrained. The $K Z$ index has been adapted in some recent empirical work by Lamont, Polk and Saa-Requejo (2001) and Baker, Stein and Wurgler (2003). In particular, Baker et al. (2003) found that the investment of firms with larger $K Z$ is more sensitive in response of $Q$. We will borrow the empirical strategy of Baker et al. (2003), with a focus on the impact of profitability forecasts on acquisition (rather than the impact of $Q$ on investment).

Forecast data are obtained from the IBES database. IBES asks analysts to provide forecasts of earnings for each firm in the database. Three variables are available: one- and two-yearahead forecasts for earnings per share, and the long-term growth forecast $(L T G)$ representing an expected annual growth in earnings over the next business cycle (a period over the next three

\footnotetext{
${ }^{45}$ This is because capital deployed in financially unconstrained firms can be affected only by the current level of technology (see equation 19). Moreover, if the news is common to all firms (e.g., news on future aggregate technological improvement), it may even exert a negative effect on capital deployed in financially unconstrained firms via the general equilibrium effect on the interest rate in (19).

${ }^{46}$ See Kaplan and Zingales (1997) for details on how to classify the firm-years into these five categories based on both objective and subjective criteria. Since firm's average $Q$ is closely related to expected future profits, we use a four-variable version of the index that omits average $Q$ (see, also, Baker, Stein and Wurgler, 2003). Using the original index does not change our main results.
} 
to five years). When calculating their forecasts of long-term growth, IBES instructs analysts to ignore the current state of the business cycle and to project, instead, the expected trend growth of the company's earnings. Thus, by the instruction of IBES, the long-term growth forecasts should contain information not in the one-year-ahead and two-year-ahead forecasts, which necessarily will be affected by current conditions. ${ }^{47}$ Instead, it captures information on variables that affect firms' profitability over the next business cycle. This objective is exactly in line with our definition of "news shocks." Therefore, we use long-term growth forecast as a proxy for "news" in our model. We use the mean of $L T G$ across analysts. ${ }^{48}$

Firm-level data on capital reallocation and variables used to construct the $K Z$ index are from Compustat. ${ }^{49}$ Compustat data distinguish between expenditure on new capital investment (Item 128) and expenditure on existing capital. Deploying existing capital can take two approaches: transfer of ownership of capital (acquisition and plant/equipment sales) and capital lease. Leasing is especially relevant for small firms, which are found to be more vulnerable to financial constraints. ${ }^{50}$ Compustat provides information on rental expenses, which include operating lease expenses in addition to other payments associated with the lease. However, measuring operating expenses for leasing existing capital is difficult. Therefore, our measurement of the size of capital reallocation $(C R)$ for each individual firm includes only acquisition (Compustat Annual Item 129) minus sale of property, plant and equipment (Item 107), though we fully realize that inclusion of leasing expenses for used capital is desirable for future research. Following Baker et al. (2003), we exclude financial firms (i.e., firms with a one-digit SIC of six) and firm-years with a book value under $\$ 10$ million, but include all observations with data on capital reallocation and the $K Z$ index.

The combination of Compustat and IBES databases results in an unbalanced panel that covers the period between 1971 and 2005. ${ }^{51}$ The full sample includes 30412 observations, for an average of 1601 observations per year. We use $C R_{t}^{i} / A T_{t-1}^{i}$ as the scaled measure of capital reallocation, where $A T$ denotes book assets (Compustat Annual Item 6). To reduce the influence of outliers, we Winsorize each of the variables used at the first and ninetyninth percentile; i.e., we set all variables beyond these tolerances to the first and ninety-ninth

\footnotetext{
${ }^{47}$ See also Cummins et al. (2006, pp. 799) for a detailed description of the construction of long-term growth forecasts by IBES.

${ }^{48}$ Using the median value of $L T G$, as recommended by IBES, gives similar results.

${ }^{49}$ All financial variables from Compustat are adjusted to 1971 USD using CPI.

${ }^{50}$ For example, using data from the 1992 Census of Manufactures, Eisfeldt and Rampini (2008b) found that firms in the smallest size decile rent more than 46 percent of their capital, while firms in the largest decile rent about 11 percent of their capital on average, and the fraction rented is monotonically decreasing across size deciles.

${ }^{51}$ The Appendix, available upon request, provides details for how to merge Compustat and IBES databases.
} 
percentile values, respectively. Our results hold qualitatively without Winsorizing the data. ${ }^{52}$ Table 7 reports summary statistics for $C R_{t}^{i} / A T_{t-1}^{i}, L T G_{t}^{i}$ and $K Z_{t}^{i}$.

Table 7. Summary Statistics

\begin{tabular}{lcccc}
\hline \hline & mean & SD & $\max$ & $\min$ \\
\hline$C R_{t}^{i} / A T_{t-1}^{i}$ & 0.0334 & 0.1076 & 0.6716 & -0.1127 \\
$L T G_{t}^{i}$ & 0.1812 & 0.0984 & 0.5367 & 0.0202 \\
$K Z_{t}^{i}$ & 0.2462 & 1.2776 & 4.1729 & -6.5283 \\
\hline
\end{tabular}

\subsection{Countercyclicality of Financial Frictions on Capital Allocation}

We now provide evidence on the first prediction: Financially constrained firms acquire more capital in boom than unconstrained firms do, while the opposite is true in recession. Put differently, we should observe that capital reallocation for financially constrained firms is more volatile along business cycles than that of unconstrained firms. As mentioned above, this implication is the prerequisite for frictions on capital allocation to be countercyclical.

We use $C R_{t}^{J} \equiv \frac{1}{N^{J}} \sum_{i \in K Z^{J}} C R_{t}^{i} / A T_{t-1}^{i}$ to measure the average size of capital reallocation for firms whose mean value of $K Z_{t}^{i}$ over the full sample period belongs to the $J$-th quintile, where $N^{J}$ refers to the number of firms in the $J$-th quintile. $\widehat{C R}_{t}^{J}$ is the cyclical component of $C R_{t}^{J}$ obtained by H-P filter. Compustat started to record acquisition (item 129) since 1971. Therefore, we have data on $\widehat{C R}_{t}^{J}$ from 1971 to 2005. Figure 8 plots $\widehat{C R}_{t}^{1}$ and $\widehat{C R}_{t}^{5}$ (i.e., size of total acquisition by firms in the bottom and top $K Z$ quintiles, respectively), together with the H-P filtered real U.S. GNP, denoted by $\widehat{G N P}_{t}$. Note that sizes of capital reallocation before 1980 are much smaller than those afterwards. It is obvious in Figure 8 that after 1980, while both of $\widehat{C R}_{t}^{1}$ and $\widehat{C R}_{t}^{5}$ are procyclical, capital reallocation for firms in the top $K Z$ quintile is much more volatile than that for firms in the bottom quintile.

\section{[Insert Figure 8]}

More precisely, Table 8 shows that the standard deviation of $\widehat{C R}_{t}^{J}$ is monotonically increasing in $J$. The increase of volatility is sizable: the variance of $\widehat{C R}_{t}^{5}$ more than doubles the variance of $\widehat{C R}_{t}^{1}$. Due to limited sizes of capital reallocation in Compustat in the 1970s, one may suspect that capital reallocation has a much smaller effect on business cycles before 1980 . For this concern, we also report results for the sub-sample period from 1981 to 2005 . We see that for that period, the monotonicity of the standard deviation of $\widehat{C R}_{t}^{J}$ along $J$ still holds.

\footnotetext{
${ }^{52}$ We Winsorize the ingredients of the $K Z$ index before constructing it.
} 
Table 8. Financial Constraint and Standard Deviation of Capital Reallocation

\begin{tabular}{lcc}
\hline \hline & Full Sample (1971-2005) & Sub-sample (1981-2005) \\
$\widehat{C R}^{1}$ & 0.0050 & 0.0051 \\
$\widehat{C R}^{2}$ & 0.0057 & 0.0073 \\
$\widehat{C R}^{3}$ & 0.0064 & 0.0082 \\
$\widehat{C R}^{4}$ & 0.0087 & 0.0098 \\
$\widehat{C R}^{5}$ & 0.0117 & 0.0153 \\
\hline
\end{tabular}

\subsection{Asymmetric Impacts of News Shocks}

It is natural to ask further what causes the countercyclicality of financial frictions on capital allocation. To this end, we test the second implication of our model: Prospects on an individual firm's future profitability affect constrained firms' capital acquisition, but not that of unconstrained firms. This hypothesis, together with the procyclicality of forecast on individual firms' future profitability, provides a micro-foundation for financial frictions on capital allocation to be countercyclical.

We apply the method of Baker et al. (2003) to test the implications. All firms in the sample data are classified into quintiles according to their mean value of $K Z_{t}^{i}$ over the full sample period. For each $K Z$ quintile, we estimate

$$
\frac{C R_{t}^{i}}{A T_{t-1}^{i}}=a_{i}+a_{t}+b \cdot L T G_{t}^{i}+u_{t}^{i},
$$

where $a_{i}$ and $a_{t}$ are firm and year dummies, respectively. Note that $L T G_{t}^{i}$ is, by definition, uncorrelated to $u_{t}^{i}$. The hypothesis implies that the estimated coefficient $b$ should be statistically insignificant for firms in lower $K Z$ quintiles, while significantly positive for firms in higher $K Z$ quintiles.

Table 9. Business Prospects and Capital Reallocation

\begin{tabular}{rccc}
\hline \hline$K Z$ index & b & Obs. & Adj. $R^{2}$ \\
\hline Quintile 1 & $\begin{array}{c}-0.0453^{*} \\
(0.021)\end{array}$ & 6075 & 0.2224 \\
2 & $\begin{array}{c}0.0032 \\
(0.021)\end{array}$ & 6084 & 0.1826 \\
3 & $\begin{array}{c}0.0857^{* *} \\
(0.023)\end{array}$ & 6086 & 0.1753 \\
4 & $\begin{array}{c}0.1194^{* *} \\
(0.026)\end{array}$ & 6078 & 0.2375 \\
5 & $0.1544^{* *}$ & 6089 & 0.2588 \\
\hline
\end{tabular}

Note: ${ }^{* *}$ and ${ }^{*}$ stand for is significant at $1 \%$ and $5 \%$, respectively. Robust standard errors are in parentheses. 
Table 9 presents the estimated results. As predicted by the theory, the estimates of $b$ are positive and highly significant for the third to fifth quintiles and not significant, or even negative, for the first two quintiles. ${ }^{53}$ Moreover, there is a strong positive correlation between $K Z$ and the effect of long-term growth forecasts on capital reallocation. The coefficient $b$ rises monotonically from 0.087 in the third quintile to 0.154 in the top quintile, suggesting that the firms that are more likely to be financially constrained have a stronger sensitivity of capital reallocation to long-term forecasts than firms that are less likely to be financially constrained.

We use the mean value of $K Z_{t}^{i}$ over the full sample period to measure the likelihood for each firm to be financially constrained. A key issue is whether the likelihood varies over time. As a robustness check, we classify firms based on their five-year mean value of $K Z_{t}^{i}$ and run the same panel regression (36) for each $K Z$ quintile. Column (1) of Table 10 shows that our main results still hold. In Column (2), we add the ratio of cash flow over $A T_{t-1}^{i}$ (Compustat Annual Item $14+$ Item 18) to the regression as control variables. ${ }^{54}$ The results are qualitatively the same as those in Table 9. As a further check, we replace $L T G$ with "long-run real $Q$ " constructed by the way proposed in Cummins et al. (2006). The long-run real $Q$ computes the two-year-ahead expected market value for each firm according to two-year-ahead earnings forecasts and the long-term growth forecasts $L T G$. One-year-ahead earnings forecasts are excluded since they are most likely affected by the current state of the economy. Column (3) of Table 10 shows that the estimates of $b$ now become positive and highly significant for each quintile. This is not surprising; the estimated $b$ is biased upwards since two-year-ahead earnings forecasts are likely correlated to $u_{t}^{i}$. However, the strong positive correlation between $K Z$ and the effect of expected market value on capital reallocation still holds. Further, the coefficient $b$ rises monotonically from 0.0034 in the bottom quintile to 0.0412 in the top quintile.

\footnotetext{
${ }^{53}$ The negative estimated $b$ may reflect the fact that firm-level variations in the expected future profitability contains information at the aggregate level. In our model, news on aggregate future technological improvement causes capital to flow from financially unconstrained to constrained firms via the general equilibrium effect.

${ }^{54}$ We multiply the one- and two-year-ahead earning forecasts per share by the number of shares outstanding to yield forecasts of future earning levels. We use a discount rate of 0.91 , as in Cummins et al. (2006). The results are insensitive to the value of the discount rate.
} 
Table 10. Robustness Check

\begin{tabular}{rccc}
\hline \hline$K Z$ index & $(1)$ & $(2)$ & $(3)$ \\
\hline Quintile 1 & -0.0092 & $-0.0493^{*}$ & $0.0034^{*}$ \\
& $(0.023)$ & $(0.021)$ & $(0.002)$ \\
2 & -0.0122 & -0.0026 & $0.0094^{* *}$ \\
& $(0.022)$ & $(0.021)$ & $(0.002)$ \\
3 & $0.0672^{*}$ & $0.069^{* *}$ & $0.0197^{* *}$ \\
& $(0.028)$ & $(0.023)$ & $(0.003)$ \\
4 & $0.0875^{* *}$ & $0.1016^{* *}$ & $0.0345^{* *}$ \\
& $(0.032)$ & $(0.026)$ & $(0.003)$ \\
5 & $0.1368^{* *}$ & $0.1126^{* *}$ & $0.0412^{* *}$ \\
& $(0.036)$ & $(0.032)$ & $(0.004)$ \\
\hline
\end{tabular}

Note: ${ }^{* *}$ and ${ }^{*}$ stand for significant at $1 \%$ and $5 \%$, respectively. Robust standard errors are in parentheses. In Column (1), we classify firms based on their five-year mean value of $K Z_{t}^{i}$. In Column (2), we add a ratio of cash flow over $A T_{t-1}^{i}$ as two control variables. Column (3) drops control variables in Column (2), but replaces $L T G$ with the long-run real $Q$ in Cummins et al. (2006). We use the sample mean of $K Z_{t}^{i}$ to classify firms in Column (2) and (3). Using five-year mean values gives qualitatively similar results.

Our firm-level evidence is consistent with the above macro evidence on capital allocation over the business cycles. This is because $L T G_{t}^{i}$ in boom periods are, on average, higher than those in recessions. For instance, the mean of $L T G_{t}^{i}$ across firms in the period of 1997-2000 is 23.71, much higher than that of 17.57 in the period of 1991-1994. Therefore, asymmetric impacts of news on capital acquisition across financially constrained and unconstrained firms, together with the procyclical movements of $L T G_{t}^{i}$, provide an explanation for the countercyclicality of financial frictions documented in the previous subsection.

In summary, we find that financial frictions on capital allocation at firm-level are countercyclical. Moreover, our empirical findings suggest a key element for business prospects to affect capital reallocation - that is, the presence of financial constraints. These, together with the findings of Basu and Fernald (2000), indicate the very channel described by our model for resource allocation to affect aggregate TFP fluctuations over business cycles: variations in financial frictions, triggered by news shocks, lead to resource reallocation and, therefore, aggregate TFP fluctuations over the business cycles.

\subsection{Frictions on New Capital Investment}

Our model assumes away financial frictions on investment. In reality, a relaxation of financial constraints might allow a firm to expand its production scale through an additional channel: investing new capital. This channel has been viewed in the literature as the leading candidate for financial frictions to play a role in business cycles. In this subsection, we examine further the empirical relevance of financial frictions on new investment over business cycles. 
To establish our empirical strategy, note that most business cycle studies that resort to financial frictions on new investment share a common feature: changes in the market prices of assets affect the degree of financial frictions via borrowing producers' net worth. Since market prices of assets are largely driven by prospects on future investment profitability, these models bear similar implications that the arrival of good (bad) news about future profitability shall relax (tighten) financial constraints. Accordingly, the presence of financial constraints magnifies the impacts of news on new capital investment. ${ }^{55}$ If financial frictions on investment are empirically relevant, we should therefore observe a significantly larger response of new capital investment to business prospects about future profitability for financially constrained firms than unconstrained ones. Hence, to test their empirical relevancy, we ask to what extent the presence of financial frictions affects the impact of business prospects on investment, and then compare the results with their counterparts in Table 9.

To make the comparison sharp, we follow exactly the same estimation strategy as before. The impact of business prospects on investment is estimated across firms along different $K Z$ quintiles. The sample firms in each $K Z$ quintile remain unchanged as those in the empirical exercise on capital reallocation. ${ }^{56}$ We run the same panel regressions as (36). The only exception is that the dependent variable now becomes investment, measured as expenditure on new capital investment, $C A P E X_{t}^{i}$ (Compustat Annual Item 128), scaled by one-period-lag book assets, $A T_{t-1}^{i}$ (Item 6).

$$
\frac{C A P E X_{t}^{i}}{A T_{t-1}^{i}}=a_{i}+a_{t}+b \cdot L T G_{t}^{i}+u_{t}^{i} .
$$

Here $a_{i}$ and $a_{t}$ are firm and year dummies, respectively.

Table 11 reports the estimation results. Compared with the estimated elasticity of capital reallocation to business prospects in Table 10, we find two key differences in the patterns of estimated $b$ for new capital investment. First, the estimates of $b$ for new capital investment are highly significant for all quintiles. By contrast, in Table 10, the estimates for capital reallocation significantly differ from zero only for the top three $K Z$ quintiles, that is, firms that are likely or definitely financially constrained. Second, while the estimated $b$ for capital reallocation monotonically increases along $K Z$ quintiles (Table 10), this pattern disappears completely when the dependent variable changes to new capital investment (Table 11). In fact, the estimates turn out to be rather stable across quintiles, ranging from the lowest of 0.12

\footnotetext{
${ }^{55}$ Note that even if financial constraints are absent, news about future profitability affects the first-best investment level.

${ }^{56}$ We exclude those firm-year observations for which investment data are missing from our sample firms for capital reallocation. This results in a sample size slightly smaller.
} 
to the highest of $0.17 . .^{57}$

Table 11: Business Prospects and Investment

\begin{tabular}{rccc}
\hline \hline$K Z$ index & $\mathrm{b}$ & Obs. & Adj. $R^{2}$ \\
\hline Quintile 1 & $0.1218^{* *}$ & 6033 & 0.5645 \\
2 & $\begin{array}{c}0.1558^{* *} \\
(0.013)\end{array}$ & 6027 & 0.5635 \\
3 & $\begin{array}{c}0.1305^{* *} \\
(0.014)\end{array}$ & 6023 & 0.5540 \\
4 & $0.1743^{* *}$ & 6036 & 0.6115 \\
5 & $\begin{array}{c}0.1588^{* *} \\
(0.170)\end{array}$ & 6045 & 0.6379
\end{tabular}

Note: ${ }^{* *}$ and ${ }^{*}$ stand for is significant at $1 \%$ and $5 \%$, respectively. Robust standard errors are in parentheses.

It is not surprising that new capital investment reacts significantly to LTG. As predicted by the standard theory, higher future profitability implies a larger first-best capital stock in the future and, therefore, more investment in the current period. Nevertheless, if financial frictions distort a firm's production scale through new capital investment, we should expect to see monotonically increasing estimates of $b$ along $K Z$ quintile in Table 11, as those in Table 9 . To the opposite, the estimates exhibit non-monotonicity and are rather stable across quintiles. The very different patterns of estimated $b$ in Table 9 and 11 help to distinguish the empirical relevance of two channels through which financial frictions affect firms' production scale over business cycles. In particular, we fail to find evidence for financial frictions to play a role through new capital investment, despite its wide acknowledgement as one of the main channels in the business cycle literature. This contrast greatly enhances the empirical plausibility of the channel highlighted in the present paper: Financial frictions on capital reallocation serve as a transmission mechanism for primitive shocks to affect aggregate productive efficiency. ${ }^{58}$

In summary, our empirical results strongly support the importance of variations in financial frictions on capital reallocation, rather than new capital investment, for individual firms' production scales. This, together with its countercyclicality, indicates that financial frictions on capital allocation is potentially important, and is empirically more plausible than financial frictions on new investment, as a transmission mechanism for primitive shocks to translate into aggregate TFP fluctuations.

\footnotetext{
${ }^{57}$ We also perform robustness check, following the same procedure as that in our previous exercise for capital reallocation (Table 10). Our two key findings remain unchanged. The results are available upon request.

${ }^{58} \mathrm{We}$ conjecture that the different patterns of the estimated $b$ between capital acquisition and new capital investment might be due to the trade-off between the time-to-build feature of new investment and the complementarity between new vintages of capital and new technology. We leave this issue for future research.
} 


\section{Conclusion}

This paper argues that financial frictions on capital allocation, rather than on new capital investment, are important as a transmission mechanism for primitive shocks to translate into aggregate TFP fluctuations. We show in a calibrated model that variations in financial frictions in response to news shocks can trigger sizable fluctuations in aggregate TFP before the actual technology change is realized. The TFP fluctuations originating from capital reallocation, furthermore, lead to business cycles by allowing positive comovement among current output, consumption, investment, and hours worked. This positive comovement, as we demonstrate, is difficult to obtain when financial frictions are imposed on new capital investment. Empirically, we find that the responses of capital acquisition to prospects about future profitability are significantly larger for firms more likely to be financially constrained, while such a pattern does not exist for new capital investment. Capital acquisition of constrained firms, furthermore, is found to be more procyclical than that for unconstrained ones. Therefore, both our theory and empirical evidence support strongly the role of financial frictions on capital allocation as a transmission mechanism of TFP fluctuations over U.S. business cycles.

Our work can be considered as a first step towards understanding TFP fluctuations over business cycles. The model developed here, as a result, has abstracted from a number of important issues. For example, in our model, entry and exit are exogenous. An endogenous entry and exit decision à la Hopenhayn (1992) can be introduced to explore the importance of financial frictions for aggregate TFP via firm entry and exit. We conjecture that introducing this extensive margin will amplify the response of aggregate TFP to primitive shocks such as news shocks. A perhaps more important issue is that we abstract from individual firm dynamics and how they interact with frictions on capital allocation. ${ }^{59}$ These abstractions also make the model silent on which firms are financially constrained. One can, instead, consider a model with a long-term financial contract to endogenize firm size distribution. It would be interesting to see how the presence of a long-term contract affects our results. Also, such a framework may help to understand how primitive shocks are propagated over business cycles.

Aside from the implications for TFP fluctuations, our model provides an alternative view of how acquisitions are related to firm values, an issue that has been often addressed in the finance literature (e.g., Jovanovic and Rousseau, 2002, and Shleifer and Vishny, 2003). One caveat is that firms in the present model are evaluated by the discounted sum of future profits. An interesting extension of the model would be to allow for production-based asset pricing,

\footnotetext{
${ }^{59}$ Consequently, the financial contract in our model is static.
} 
so that stock market valuations of firms and reallocations of capital interact over time. This might eventually explain the puzzling joint behavior of aggregate TFP and stock prices found by Beaudry and Portier (2006).

\section{Appendix}

\subsection{Enforcement Constraint}

The renegotiation process described here follows closely from Jermann and Quadrini (2006). Assume that production of a type- $h$ project at each period requires an amount of working capital, denoted as $f_{t}=D\left(K_{t}^{h}\right)$ (or $D\left(K_{t}^{h}, H_{t}^{h}\right)$ in the full-blown economy), with $D^{\prime}(\cdot)>0$. Working capital consists of liquid funds that are used at the beginning of time $t$ and are recovered at the end of time $t$, after all transactions have been completed. Because this is an intra-period loan, the net interest payment is zero.

Entrepreneurs have the ability to divert working capital and default. ${ }^{60}$ Once the entrepreneur defaults, the lender can take over the control right of the project and recover a fraction $\varphi$ of the future project value, denoted as $V_{t+1}^{h}$, which is the simply the present discount value of the project profits from tomorrow on. Here, the underlying assumption is that only the entrepreneur has the required talent to run this project efficiently. Denote by $\omega$ the bargaining power of the entrepreneur and by $1-\omega$ the bargaining power of the lender. Bargaining is over the repayment of the debt, denoted as $\widehat{f}_{t}$. If they reach an agreement, the entrepreneur gets $f_{t}-\widehat{f}_{t}+V_{t+1}^{h}$, and the lender gets $\widehat{f}_{t}$, If there is no agreement, the entrepreneur gets $f_{t}$ and the lender gets $\varphi V_{t+1}^{i}$. Therefore, the net value for the entrepreneur to reach an agreement is $V_{t+1}^{h}-\widehat{f}_{t}$ and the net value for lender is $\widehat{f}_{t}-\varphi V_{t+1}^{h}$. The bargaining problem solves:

$$
\max _{\widehat{f_{t}}}\left\{\left(V_{t+1}^{h}-\widehat{f}_{t}\right)^{\omega}\left(\widehat{f}_{t}-\varphi V_{t+1}^{h}\right)^{1-\omega}\right\}
$$

Taking the first-order condition, we get $\widehat{f}_{t}=[1-\omega(1-\varphi)] V_{t+1}^{h}$. Incentive compatibility requires that the value of non-default for the entrepreneur, $V_{t+1}^{h}$, should be no less than the value of default, which is $f_{t}-\widehat{f}_{t}+V_{t+1}^{h}$. Hence, we have

$$
[1-\omega(1-\varphi)] V_{t+1}^{h} \geq f_{t}
$$

Denote $[1-\omega(1-\varphi)]$ as $\theta$. Then we get (1) (or (16) in the full-blown model).

\footnotetext{
${ }^{60}$ Similarly, Hart and Moore (1998) assume that beyond the project cost, a fraction of the loan that the debtor receives from the creditor represents the non-recourse financing, which is not seizable by the creditor.
} 


\subsection{Definition of Recursive Competitive Equilibrium for the Full-blown Economy}

This section sketches out the definition of the recursive competitive equilibrium for our benchmark economy. To simplify notation, we abstract from population and denote lower-case variables as individual variables and upper-case variables as aggregate variables. In our benchmark economy with news shocks on $Z_{t}$, the state variables for the households are $s_{t}=\left(Z_{t}, \epsilon_{t}^{Z}, k_{t}, K_{t}\right)$ or simply $\left(Z_{t}, Z_{t+1}, k_{t}, K_{t}\right)$ since next-period aggregate technology is perfectly predictable by (9). Because entrepreneurs' optimization problems at each period are static, we need only specify the household's problem recursively. The household's problem can be rewritten as

$$
v\left(Z, Z^{\prime}, k, K\right)=\max _{c, i, h}\left\{u(c, h)+\beta E\left[v\left(Z^{\prime}, Z^{\prime \prime}, k^{\prime}, K^{\prime}\right) \mid Z^{\prime}\right]\right\}
$$

subject to

$$
\begin{aligned}
c+i+\kappa\left(\frac{i}{k}-\delta-n-g_{y}\right)^{2} k & =\left(r\left(Z, Z^{\prime}, K\right)+\delta\right) k+w\left(Z, Z^{\prime}, K\right) h+(1-\eta) \pi^{l}+\eta \pi^{h} . \\
k^{\prime} & =(1-\delta) k+i \\
K^{\prime} & =(1-\delta) K+I\left(Z, Z^{\prime}, K\right) \\
\log Z^{\prime} & =\rho \log Z+\epsilon^{Z}
\end{aligned}
$$

A recursive competitive equilibrium for this economy consists of a value function, $v\left(Z, Z^{\prime}, k, K\right)$; a set of decision rules $c\left(Z, Z^{\prime}, k, K\right), i\left(Z, Z^{\prime}, k, K\right), h\left(Z, Z^{\prime}, k, K\right)$ for the household; a corresponding set of aggregate per capita decision rules, $C\left(Z, Z^{\prime}, K\right), I\left(Z, Z^{\prime}, K\right), H\left(Z, Z^{\prime}, K\right)$; a set of decision rules for the entrepreneurs, $K^{h}\left(Z, Z^{\prime}, K\right), H^{h}\left(Z, Z^{\prime}, K\right), K^{l}\left(Z, Z^{\prime}, K\right)$, $H^{l}\left(Z, Z^{\prime}, K\right)$ and factor prices functions $r\left(Z, Z^{\prime}, K\right), w\left(Z, Z^{\prime}, K\right)$, such that these functions satisfy

1. The household's problem (38);

2. The entrepreneurs' problem (17);

3. The consistency of individual and aggregate decisions - that is, $c\left(Z, Z^{\prime}, k, K\right)=C\left(Z, Z^{\prime}, K\right)$, $i\left(Z, Z^{\prime}, k, K\right)=I\left(Z, Z^{\prime}, K\right)$ and $h\left(Z, Z^{\prime}, k, K\right)=H\left(Z, Z^{\prime}, K\right)$. 
4. The aggregate resource constraint

$$
\begin{aligned}
& C\left(Z, Z^{\prime}, K\right)+I\left(Z, Z^{\prime}, K\right)+\kappa\left(\frac{I\left(Z, Z^{\prime}, K\right)}{K}-\delta-n-g_{y}\right)^{2} K=Y\left(Z, Z^{\prime}, K\right) \\
= & \eta A^{h}\left(\left(K^{h}\left(Z, Z^{\prime}, K\right)\right)^{\alpha}\left(H^{h}\left(Z, Z^{\prime}, K\right)\right)^{1-\alpha}\right)^{\mu} \\
& +(1-\eta) A^{l}\left(\left(K^{l}\left(Z, Z^{\prime}, K\right)\right)^{\alpha}\left(H^{l}\left(Z, Z^{\prime}, K\right)\right)^{1-\alpha}\right)^{\mu}, \forall\left(Z, Z^{\prime}, K\right) .
\end{aligned}
$$

\subsection{Non-existence of NDBC with Frictions on New Capital Investment}

In this section, we prove that there exist no news-driven business cycles in an environment with frictions on new capital investment. Consider a two-sector economy in which the production function for consumption goods and the production function for investment goods are distinct. This economy differs from the standard two-sector economy in that the investment good sector is constrained. A social planner maximizes the expected utility of a representative household.

$$
\max _{c_{t}, h_{t}, i_{t}} E_{0}\left[\sum_{t=0}^{\infty} \beta^{t} u\left(c_{t}, h_{t}\right)\right]
$$

subject to

$$
\begin{aligned}
c_{t} & =G\left(k_{t}, h_{t}, i_{t}\right) \\
k_{t+1} & =(1-\delta) k_{t}+i_{t} \\
i_{t} & \leq M_{t}
\end{aligned}
$$

where

$$
G\left(k_{t}, h_{t}, i_{t}\right)=\max _{k_{t}^{c}, k_{t}^{i}, h_{t}^{c}, h_{t}^{i}} F^{c}\left(k^{c}, h^{c}\right)
$$

subject to

$$
\begin{aligned}
F^{i}\left(k_{t}^{i}, h_{t}^{i}\right) & \geq i_{t} \\
k_{t}^{c}+k_{t}^{i} & \leq k_{t} \\
h_{t}^{c}+h_{t}^{i} & \leq h_{t}
\end{aligned}
$$

That is, we may solve the problem of optimal consumption and investment in a recursive way: Given some $i_{t}$, which may be constrained by (41), we solve for the optimal consumption by (42) . Then, given the optimal policy response of $c_{t}$ to $i_{t}$, we solve for the optimal $i_{t}$ by (39) .

Note that in our specification of the financial constraint on investment (41), $M_{t}$ may correspond to collateral value that is linked to future profit (e.g., stock value). This allows an 
expected increase in future TFP to increase $M_{t}$ and, therefore, relax the constraint (41). We now prove that an increase in $i_{t}$ caused by an increase in $M_{t}$ must be associated with a decline in $c_{t}$ and $h_{t}$. To generalize, we assume that $F^{c}$ and $F^{i}$ are homogeneous of degree $\theta$, where $\theta \leq 1$. Specifically

$$
F^{j}\left(k_{t}^{j}, h_{t}^{j}\right)=\left(\left(k_{t}^{j}\right)^{\alpha}\left(h_{t}^{j}\right)^{1-\alpha}\right)^{\theta}, j=c \text { or } i
$$

We prove our claim following the strategy adopted by Beaudry and Portier (2007). Since the production function is homogeneous, we can rewrite the problem (42) in its dual form - i.e., cost minimization. Let $\Omega^{c}\left(r_{t}, w_{t}\right)$ represent the unit cost associated with one unit of consumption good and $\Omega^{i}\left(r_{t}, w_{t}\right)$ be the unit cost associated with one unit of investment good. Note that since the production function may be decreasing returns to scales, $\Omega^{c}\left(r_{t}, w_{t}\right.$ ) (and $\left.\Omega^{i}\left(r_{t}, w_{t}\right)\right)$ may depend on the amount of consumption goods (investment goods) produced. To solve for $\Omega^{c}\left(r_{t}, w_{t}\right)$ and $\Omega^{i}\left(r_{t}, w_{t}\right)$, let's look at the general case

$$
\min _{k_{t}, h_{t}} r_{t} k_{t}^{j}+w_{t} h_{t}^{j}
$$

subject to

$$
F\left(k_{t}^{j}, h_{t}^{j}\right) \geq y_{t}
$$

where $j=c$ or $i, y_{t}$ can be $c_{t}$ or $i_{t}$. Solving for this problem, the first-order conditions imply

$$
\frac{w_{t}}{r_{t}}=\frac{k_{t}^{j}}{h_{t}^{j}} \frac{1-\alpha}{\alpha} \text {. }
$$

Combining (43) and (44), we get

$$
\begin{aligned}
k_{t}^{j} & =y_{t}^{\frac{1}{\theta}}\left(\frac{\alpha w_{t}}{(1-\alpha) r_{t}}\right)^{1-\alpha} \\
h_{t}^{j} & =y_{t}^{\frac{1}{\theta}}\left(\frac{(1-\alpha) r_{t}}{\alpha w_{t}}\right)^{\alpha}
\end{aligned}
$$

The unit cost $\Omega^{j}\left(r_{t}, w_{t}\right)$ follows

$$
\Omega^{j}\left(r_{t}, w_{t}\right)=\frac{r_{t} k_{t}^{j}+w_{t} h_{t}^{j}}{y_{t}}=\left(\frac{r_{t}}{\alpha}\right)^{\alpha}\left(\frac{w_{t}}{1-\alpha}\right)^{1-\alpha} y_{t}^{\frac{1}{\theta}-1} .
$$

Moreover, (45) implies that for $c_{t}$,

$$
k_{t}^{c}=c_{t} \Omega_{1}^{c}\left(r_{t}, w_{t}\right)
$$

where $\Omega_{1}^{c}\left(r_{t}, w_{t}\right)$ is the derivative of $\Omega^{c}\left(r_{t}, w_{t}\right)$ with respect to its first argument. According to $(47)$,

$$
\Omega_{1}^{c}\left(r_{t}, w_{t}\right)=c_{t}^{\frac{1}{\theta}-1}\left(\frac{\alpha w_{t}}{(1-\alpha) r_{t}}\right)^{1-\alpha}
$$


Similarly for $i_{t}$, we have

$$
k_{t}^{i}=i_{t} \Omega_{1}^{i}\left(r_{t}, w_{t}\right) .
$$

Therefore, the resource constraint for $k$ becomes

$$
c_{t} \Omega_{1}^{c}\left(r_{t}, w_{t}\right)+i_{t} \Omega_{1}^{i}\left(r_{t}, w_{t}\right)=k_{t} .
$$

Similarly, the resource constraint for $h$ becomes

$$
c_{t} \Omega_{2}^{c}\left(r_{t}, w_{t}\right)+i_{t} \Omega_{2}^{i}\left(r_{t}, w_{t}\right)=h_{t}
$$

Finally, we use the first-order conditions for consumption goods that $r_{t}=\theta \alpha c_{t} / k_{t}^{c}$ and $w_{t}=$ $\theta(1-\alpha) c_{t} / h_{t}^{c}$. (47) establishes that

$$
\Omega^{c}\left(r_{t}, w_{t}\right)=\theta
$$

Note that when the production function is constant returns to scale $(\theta=1)$, the unit cost $\Omega^{c}\left(r_{t}, w_{t}\right)=1$. Therefore, an equilibrium must satisfy (51) and the following first-order conditions:

$$
-u_{2}\left(c_{t}, h_{t}\right)=w_{t} u_{1}\left(c_{t}, h_{t}\right)
$$

We now show that an increase in $i_{t}$ due to a relaxation of constraint (41) must be associated with a decrease in $c_{t}, h_{t}$ or both. Let's assume the opposite - that is, both $c_{t}$ and $h_{t}$ increase. Then, (52) implies that $w_{t}$ has to increase. Then, according to (51), $r_{t}$ has to decrease. Together, this implies from (48) that $\Omega_{1}^{c}\left(r_{t}, w_{t}\right)$ shall increase. A similar argument implies that

$\Omega_{1}^{i}\left(r_{t}, w_{t}\right)$ shall increase. This violates resource constraint (49). Hence, there is no positive comovement between $i_{t}$ and $c_{t}$ or $h_{t}$ in this two-sector economy.

\subsection{Tables}

Table A-1. Volatility of Macro Variables in the Economy w/o Labor

\begin{tabular}{lcc}
\hline \hline & Data & Model \\
\cline { 2 - 3 } & & \\
\hline Used for calibration & 0.0125 & 0.0124 \\
the standard deviation of TFP & & \\
$\begin{array}{l}\text { Not used for calibration } \\
\text { the standard deviation of output }\end{array}$ & 0.0173 & 0.0123 \\
the standard deviation of consumption & 0.0120 & 0.0058 \\
the standard deviation of investment & 0.0597 & 0.0393 \\
\hline
\end{tabular}


Table A-2. Cross-Correlation Table in the Full-Blown Model

\begin{tabular}{llllll}
\hline \hline & $\mathrm{t}-2$ & $\mathrm{t}-1$ & $\mathrm{t}$ & $\mathrm{t}+1$ & $\mathrm{t}+2$ \\
\cline { 2 - 6 } & \multicolumn{5}{c}{ Data } \\
\cline { 2 - 6 } correlation(Y,Y) & -0.0214 & 0.5565 & 1.0000 & 0.5527 & -0.0463 \\
correlation(C,Y) & -0.1948 & 0.3038 & 0.7186 & 0.7153 & 0.4458 \\
correlation(I,Y) & 0.2357 & 0.6444 & 0.8540 & 0.1967 & -0.4495 \\
correlation(H,Y) & 0.0316 & 0.5168 & 0.9343 & 0.5049 & -0.1705 \\
correlation(TFP,Y) & 0.4162 & 0.6279 & 0.4099 & -0.3638 & -0.6303 \\
\hline & \multicolumn{5}{c}{ News on $Z_{t}$} \\
correlation(Y,Y) & 0.0918 & 0.5275 & 1.0000 & 0.5283 & 0.0901 \\
correlation(C,Y) & 0.0906 & 0.5466 & 0.9993 & 0.5349 & 0.1029 \\
correlation(I,Y) & 0.0938 & 0.4851 & 0.9966 & 0.5118 & 0.0629 \\
correlation(H,Y) & 0.0478 & 0.4437 & 0.9951 & 0.5524 & 0.1191 \\
correlation(TFP,Y) & 0.2021 & 0.6329 & 0.9799 & 0.4211 & -0.0402 \\
\hline & \multicolumn{5}{c}{ News on $\chi_{t}^{h}$} \\
correlation(Y,Y) & 0.1239 & 0.6598 & 1.0000 & 0.6611 & 0.1268 \\
correlation(C,Y) & 0.1738 & 0.7473 & 0.9762 & 0.5386 & 0.0753 \\
correlation(I,Y) & -0.0051 & 0.3530 & 0.8765 & 0.8202 & 0.2263 \\
correlation(H,Y) & 0.1200 & 0.7332 & 0.8173 & 0.3591 & 0.1433 \\
correlation(TFP,Y) & 0.1732 & 0.6660 & 0.9920 & 0.6362 & 0.0529 \\
\hline
\end{tabular}




\section{References}

[1] Atkeson A. and P. Kehoe (2001), "The Transition to a New Economy after the second Industrial Revolution," Minneapolis Fed Working Paper \#606

[2] Baker, M., J. Stein and J. Wurgler (2003), "When does the Market Matter? Stock Prices and The Investment of Equity-Dependent Firms," Quarterly Journal of Economics, v118, 969-1006

[3] Barseghyan L. and R. Dicecio (2005), "Heterogeneous Firms, Productivity, and Poverty Traps", Federal Reserve Bank of St. Louis, Working Paper

[4] Bartelsman, E. and M. Doms (2001), "Understanding Productivity: Lessons from Longitudinal Microdata", Journal of Economic Literature, 38, 569-594

[5] Bartelsman, E. and P. Dhrymes (1998), "Productivity Dynamics: U.S. Manufacturing Plants, 1979-1996," Journal of Productivity Analysis, 9, 5-34

[6] Basu, S. and J. Fernald (1997), "Returns to Scale in U.S. Production: Estimates and Implications," Journal of Political Economy, 105, 249-283

[7] Basu, S. and J. Fernald (2000), "Why is Productivity Procyclical? Why do we care?", NBER working paper, 7940

[8] Beaudry, P. and F. Portier (2004), "An Exploration into Pigou's Theory of Cycles," Journal of Monetary Economics, 51, 1183-1216

[9] Beaudry, P. and F. Portier (2006), "Stock Prices, News and Economic Fluctuations," American Economic Review, September, 1293-1307

[10] Beaudry, P. and F. Portier (2007), "When can Changes in Expectations case Business Cycle Fluctuations in Neo-classical Setting?", Journal of Economic Theory, 135, 458-477

[11] Bernanke, B. and M. Gertler (1989), "Agency Costs, Net Worth, and Business Fluctuations," The American Economic Review, 79, 14-31

[12] Bernanke, B. M. Gertler and S. Gilchrist (1998), "The Financial Accelerator in A Quantitative Business Cycle Framework," in Handbook of Macroeconomics

[13] Buera, F. J. and Y. Shin (2008), "Financial Frictions and the Persistence of History: A Quantitative Exploration", University of Wisconsin, working paper 
[14] Caballero, R. J. and M.L. Hammour (1994), " The Cleansing Effect of Recessions," The American Economic Review, 84, 1350-1368

[15] Caballero, R. J. and M.L. Hammour (2005), "The Cost of Recession Revisited: A ReverseLiquidationist View," Review of Economic Studies, 72, 313-341

[16] Carpenter, R. and B. Peterson (2002), "Capital Market Imperfections, High-Tech Investment, and New Equity Financing," The Economic Journal 112 (477), 54-72

[17] Carlstrom, C. and T. Fuerst (1997), "Agency Costs, Net Worth, and Business Fluctuations: A Computable General equilibrium Analysis," The American Economic Review, December, 893-910

[18] Christiano, L. R. Motto and M. Rostagno (2006), "Monetary Policy and Stock Market Boom-Bust Cycles", manuscript, Northwestern University and European Central Bank

[19] Cooley, T., R. Marimon and V. Quadrini (2004), "Aggregate Consequences of Limited Contract Enforceability", Journal of Political Economy, 112(4), 817-847

[20] Cooley, T. and E. Prescott (1995), "Economic Growth and Business Cycles," in Frontiers of Business Cycle Research, ed. by T.F. Cooley, 1-38 Princeton, Princeton University Press

[21] Cooper, R. and J. Haltiwanger (2006), "On the Nature of Capital Adjustment Costs," Review of Economic Studies, 73 (3), 611-633

[22] Cummins, J., K. Hassett, and S. Oliner (2006), "Investment behavior, Observable Expectations and Internal Funds," American Economic Review, 96(3), 796-810

[23] Danthine, J.-P., J.B. Donaldson and T. Johnsen (1998), "Productivity Growth, Consumer Confidence and the Business Cycle, " European Economic Review, 42, 1113-1140

[24] Davis, S. and J. Haltiwanger (1990), "Gross Job Creation and Destruction: Microeconomic Evidence and Macroeconomic Implications," in Blanchard, O. and S. Fisher (Eds.) NBER Macroeconomic Annual, MIT Press, Cambridge, 123-168

[25] Den Haan, W. and G. Kaltenbrunner (2006), "Anticipated Growth and Business Cycles in a matching Models", working paper

[26] Eisfeldt, A. and A. Rampini (2006), "Capital Reallocation and Liquidity," Journal of Monetary Economics, 119 (3), 899-927 
[27] Eisfeldt, A. and A. Rampini (2008a), "Managerial Incentive, Capital Reallocation, and The Business Cycle", Journal of Financial Economics, 87, 177-199

[28] Eisfeldt, A. and A. Rampini (2008b), "Leasing, Ability to Repossess, and Debt Capacity", Review of Financial Studies, 21, forthcoming

[29] Erosa, A. and A. H, Cabrillana (2007), "On Finance as a Theory of TFP, Cross-Industry Productivity Differences, and Economic Rents," forthcoming, International Economic Review

[30] Fazzari, S. and B. Petersen (1993), "Working Capital and Fixed Investment: New Evidence on Financing Constraint," RAND Journal of Economics, 24, 328-342

[31] Gilchrist, S. and C. Himmelberg (1995), "Evidence on the Role of Cash Flow for Investment," Journal of Monetary Economics, December 1995, 36(3), 541-572

[32] Greenwood, J., Z. Hercowitz and G. Hoffman (1988), "Investment, Capacity Utilization and the Real Business Cycle," American Economic Review, 78, 402-417

[33] Harford, J. (2005), "What Drives Merger Waves", Journal of Financial Economics, 77, $529-560$

[34] Hart, O. and J. Moore (1998), "Default and Renegotiation: A Dynamic Model of Debt," Quarterly Journal of Economics, 1-41

[35] Hopenhayn, H. (1992), "Entry, Exit, and Firm Dynamics in Long Run Equilibrium", Econometrica, 60, 1127-1150

[36] Jaimovich, N. and S. Rebelo (2006), "Can News About the Future Drive the Business Cycles", working paper, Northwestern University.

[37] Jensen, M. (1986), "The Agency Cost of Free Cash Flow: Corporate Finance and Takeover," American Economic Review, 76(2), 323-330

[38] Jermann, U. and V. Quadrini (2007), "Stock Market Boom and the Productivity Gains of the 1990s", Journal of Monetary Economics, 54(2), 413-432

[39] Jermann, U. and V. Quadrini (2006), "Financial Innovations and Macroeconomic Volatility," NBER working paper, 12308

[40] Jovanovic B. and P. Rousseau (2002), "The Q-Theory of Mergers", AEA Papers and Proceedings, 198-204 
[41] Kaplan, S, and L. Zingales (1997), "Do Investment-cash Flow Sensitivities Provide Useful Measures of Financial Constraints?," Quarterly Journal of Economics, 112, 169-215

[42] King, R., C. Plosser and S. Rebelo (1988), "Production, Growth and Business Cycles: I, The Basic Neoclassical Model," Journal of Monetary Economics, 21, 195-232

[43] Kiyotaki, N. and J. Moore (1997), "Credit Cycles", Journal of Political Economy, 105 (2), 211-248

[44] Lamont, O. C. Polk, and J. Saa-Requejo (2001), "Financial Constraints and Stock Returns," Review of Financial Studies, 14, 529-554

[45] Lucas, J. R. (1978), "On the Size Distribution of Business Firms", The Bell Journal of Economics, 9 (2) 508-523

[46] Maksimovic, V. and P. Gordon (2001), "The Market for Corporate Assets: Who Engages in mergers and Asset sales and Are There Gains?" Journal of Finance, LVI (6), 2019-2065

[47] OECD (2001), "Productivity and Firm Dynamics: Evidence from Microdata," Economic Outlook, 69(1), 209-223

[48] Opler, T., L. Pinkowitz, R. Stulz and R. Williamson (1999), "The Determinats and Implications of Corporate Cash Holdings," Journal of Financial Economics, 52, 3-46

[49] Restuccia, D. and R. Rogerson (2008), "Policy Distortions and Aggregate Productivity with Heterogeneous Plants," forthcoming, Review of Economic Dynamics

[50] Shleifer A. and R. Vishny (2003), "Stock Market Driven Acquisitions", Journal of Financial Economics, 70, 295-311

[51] Syverson, C. (2004), "Product Substitutability and Productivity Dispersion," Review of Economics and Statistics, 86 (2), 534-550

[52] Tauchen, G. and R. Hussey (1991), "Quadrature Based Methods for Obtaining Approximate Solutions to Nonlinear Asset Pricing Models," Econometrica, 371-396 

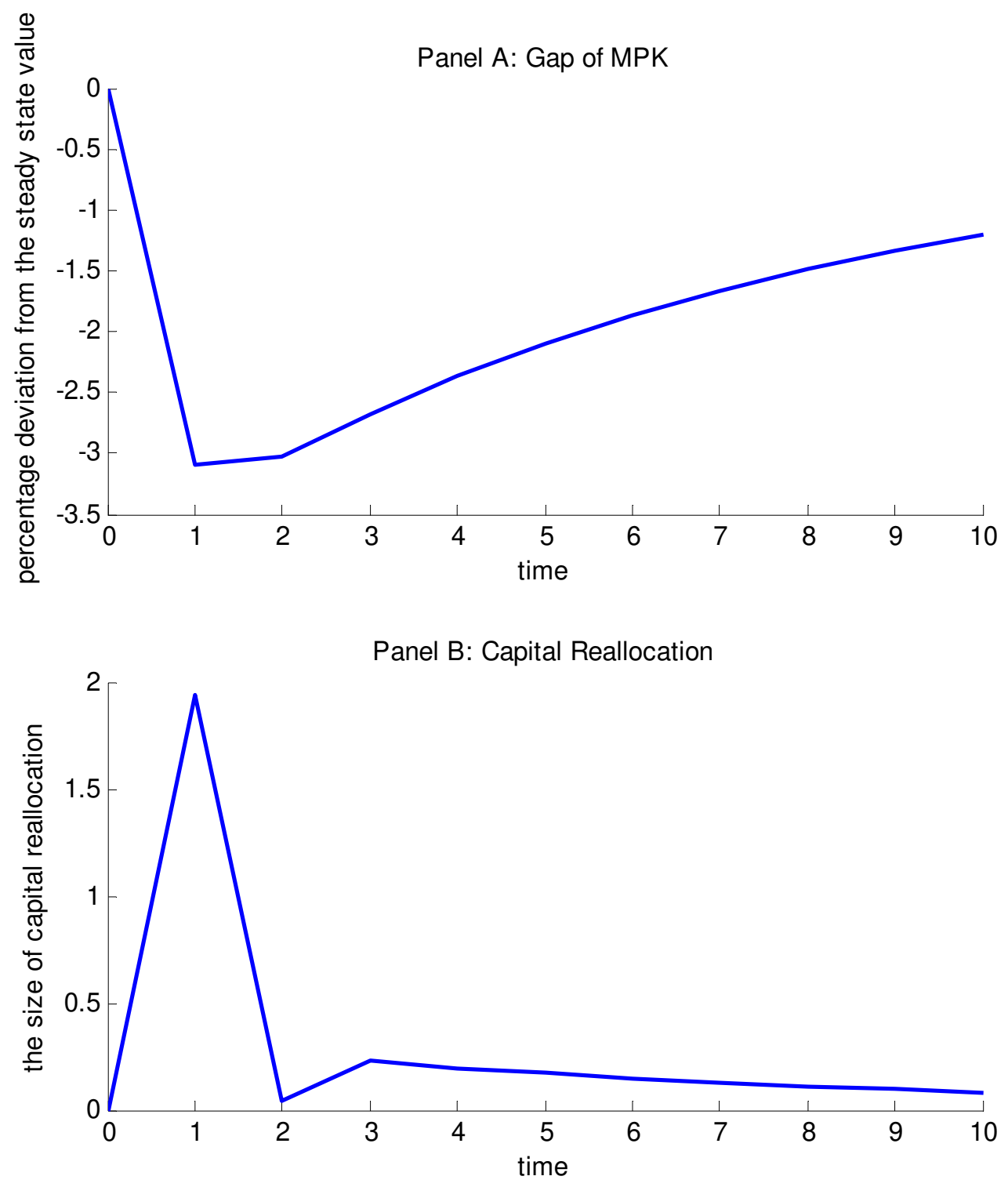

Figure 1: Response of Capital Reallocation to News Shock in Aggregate Technology in the Economy w/o Labor. 


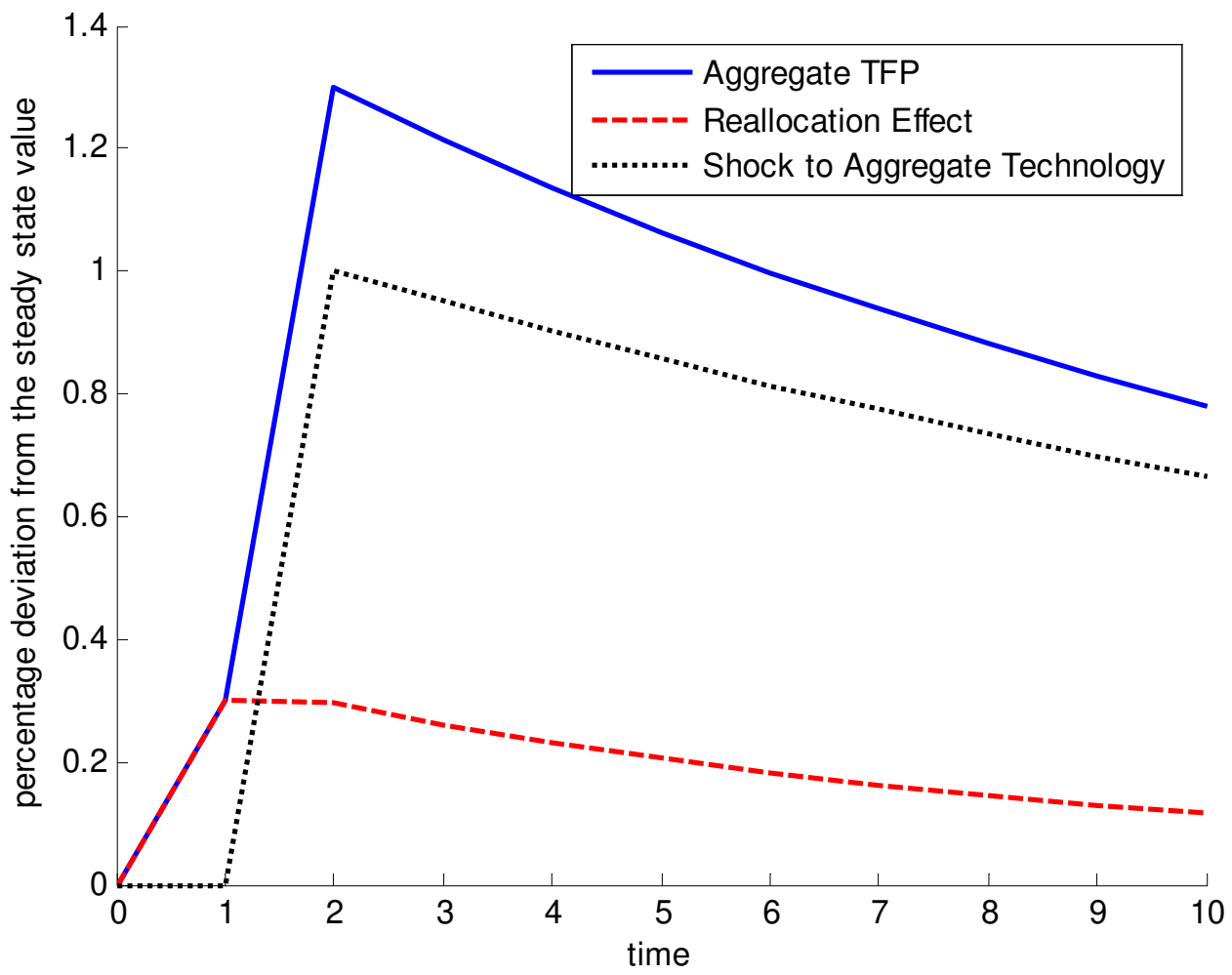

Figure 2: Response of Aggregate TFP and its Components to News Shock on Aggregate Technology in the Economy w/o Labor. 


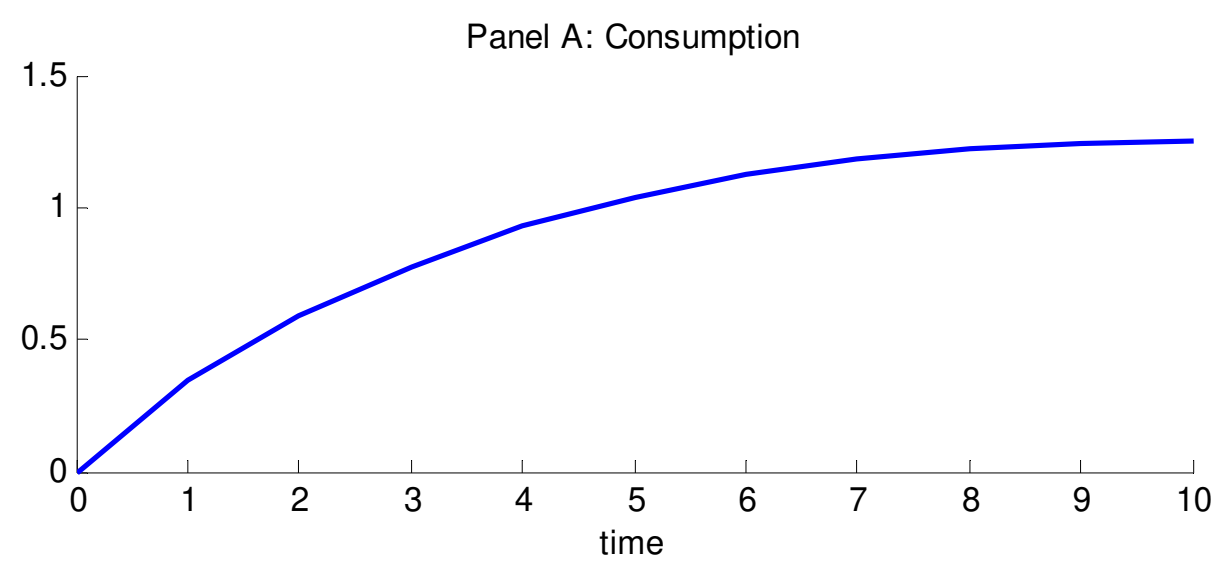

Panel B: Investment

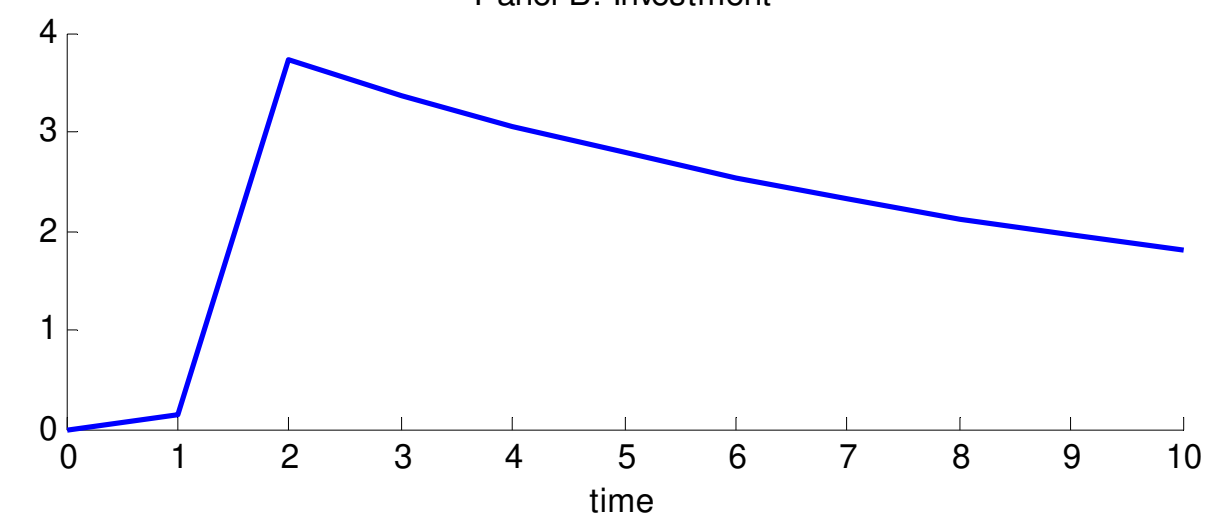

Panel C: Aggregate Output

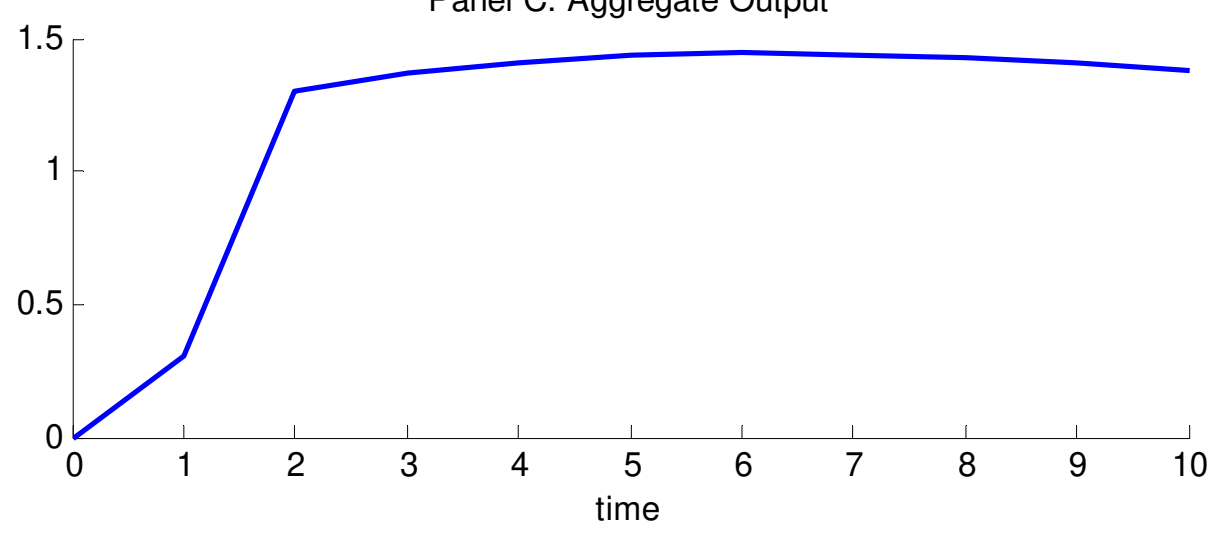

Figure 3: Percentage Deviations from the Steady State Value of Consumption, Investment and Aggregate Output in Response to News Shock on Aggregate Technology in the Economy w/o Labor. 

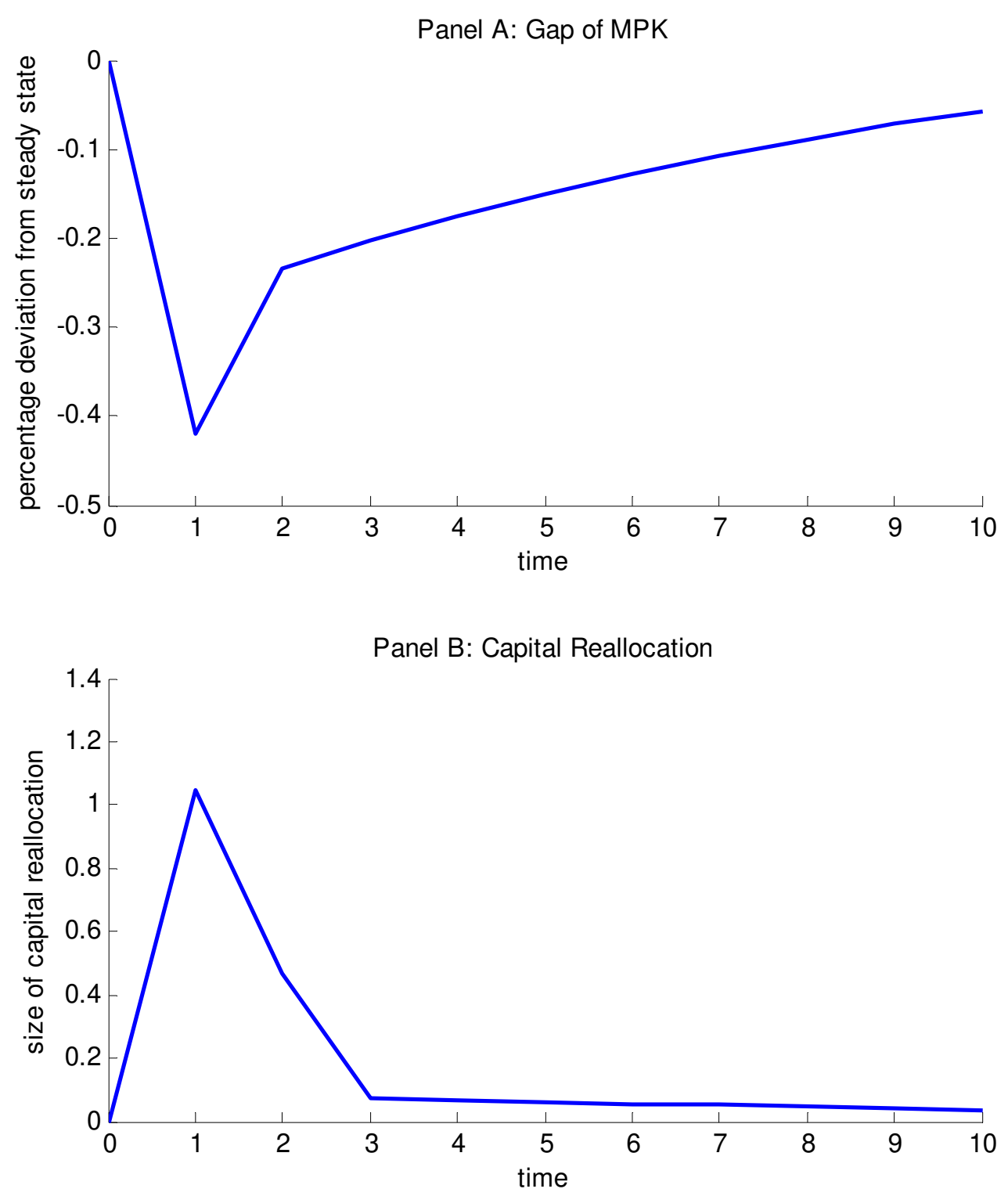

Figure 4: Response of Capital Reallocation to News Shock on Aggregate Technology in the Full-Blown Economy. 


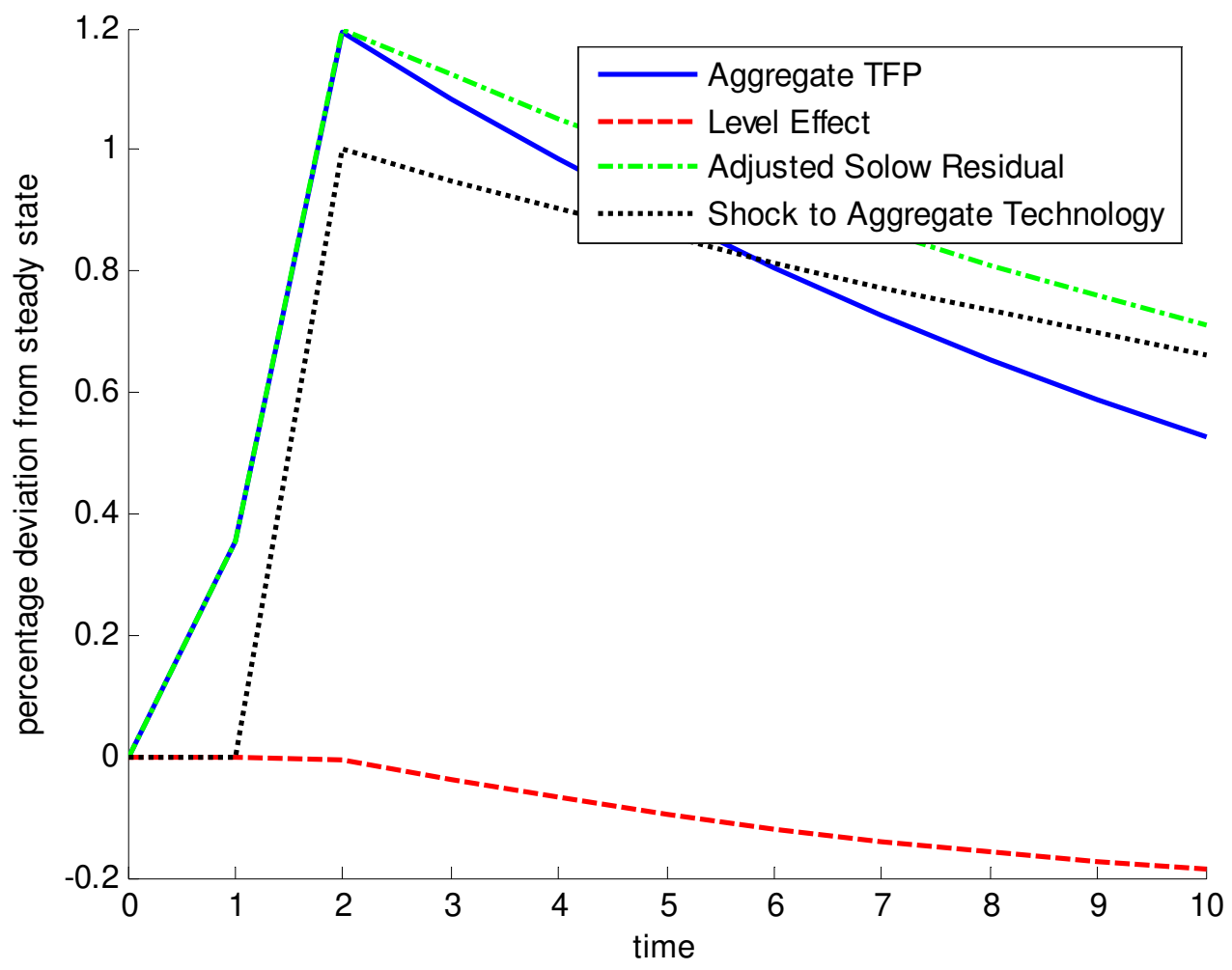

Figure 5: Response of Aggregate TFP and its Components to News Shock on Aggregate Technology in the Full-Blown Economy. 


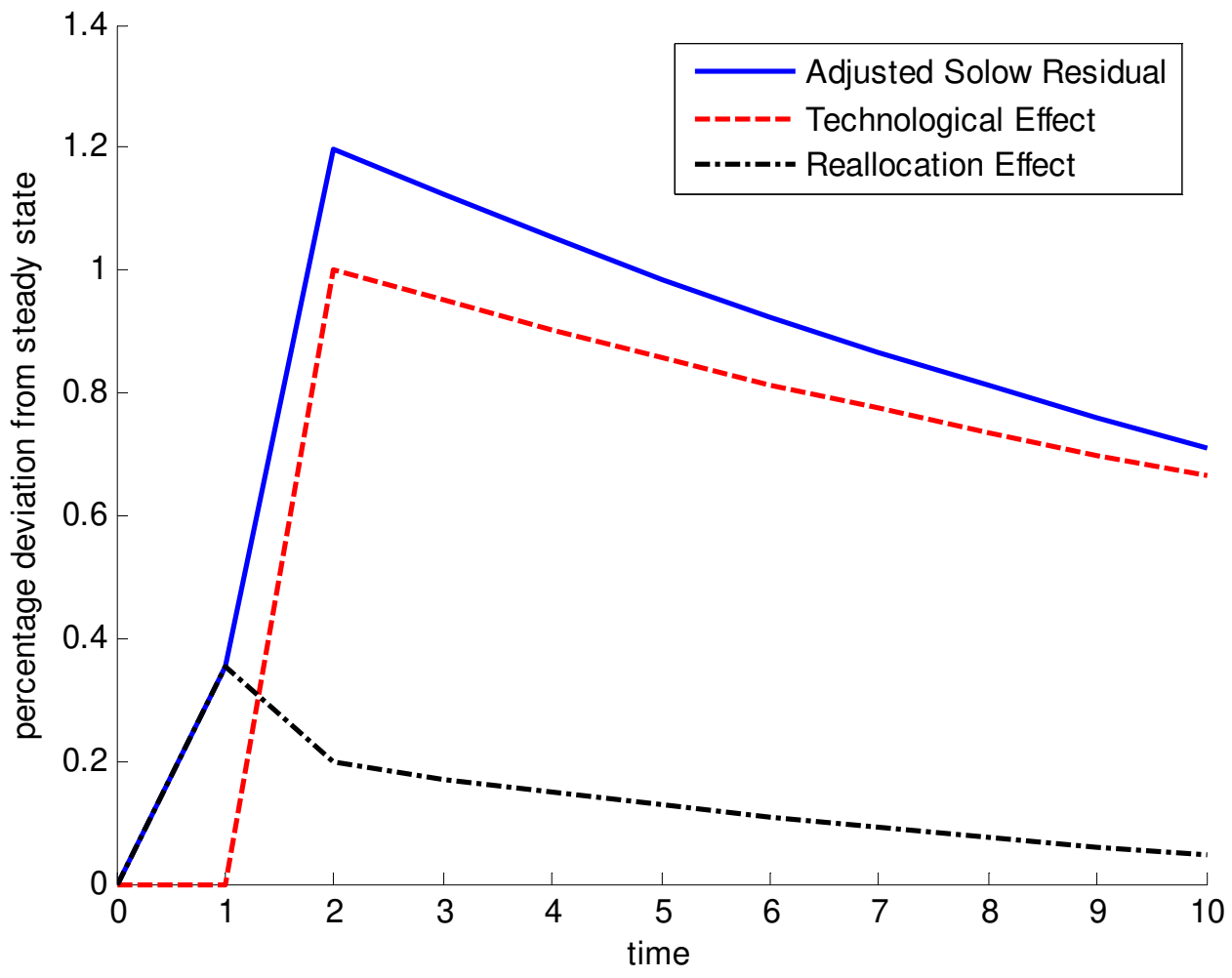

Figure 6: Response of Adjusted Solow Residual and its Components to News Shock on Aggregate Technology in the Full-Blown Economy. 
Panel A: Consumption

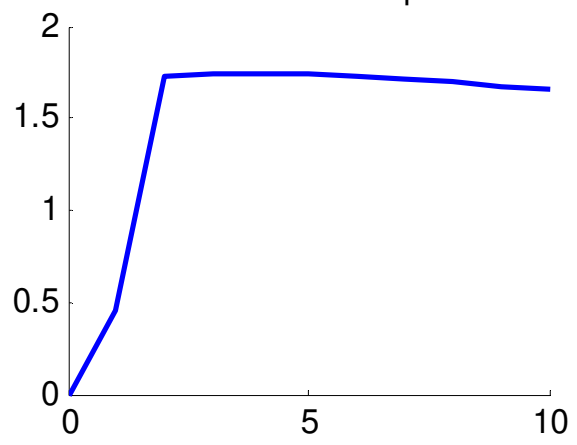

Panel C: Aggregate Output

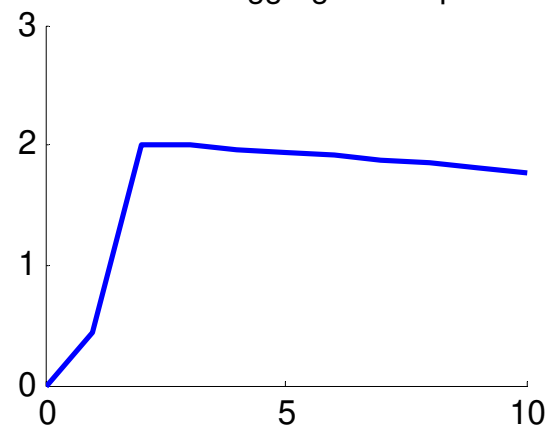

Panel B: Investment

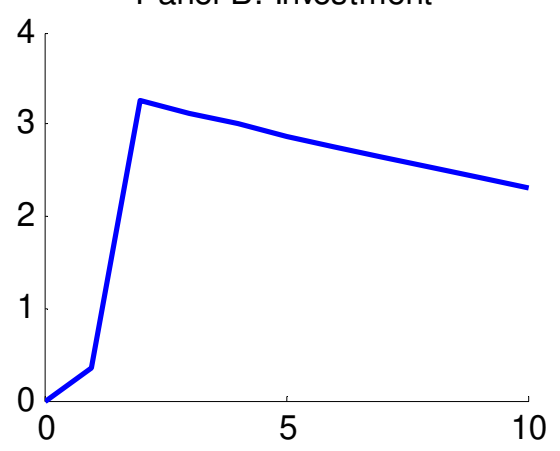

Panel D: Aggregate Labor Supply

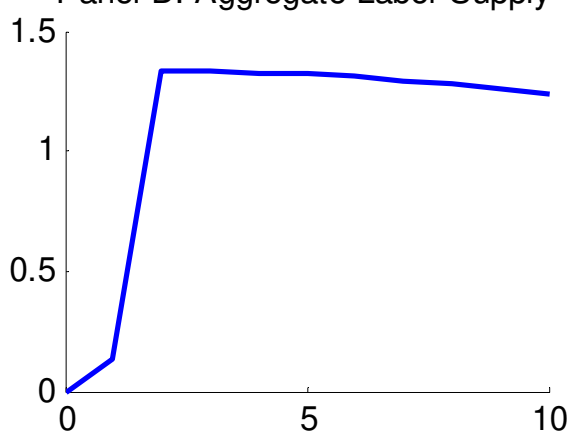

Figure 7: Percentage Deviations from the Steady State Value of Consumption, Investment, Aggregate Output and Labor Supply in Response to News Shock on Aggregate Technology in the Full-Blown Economy. 


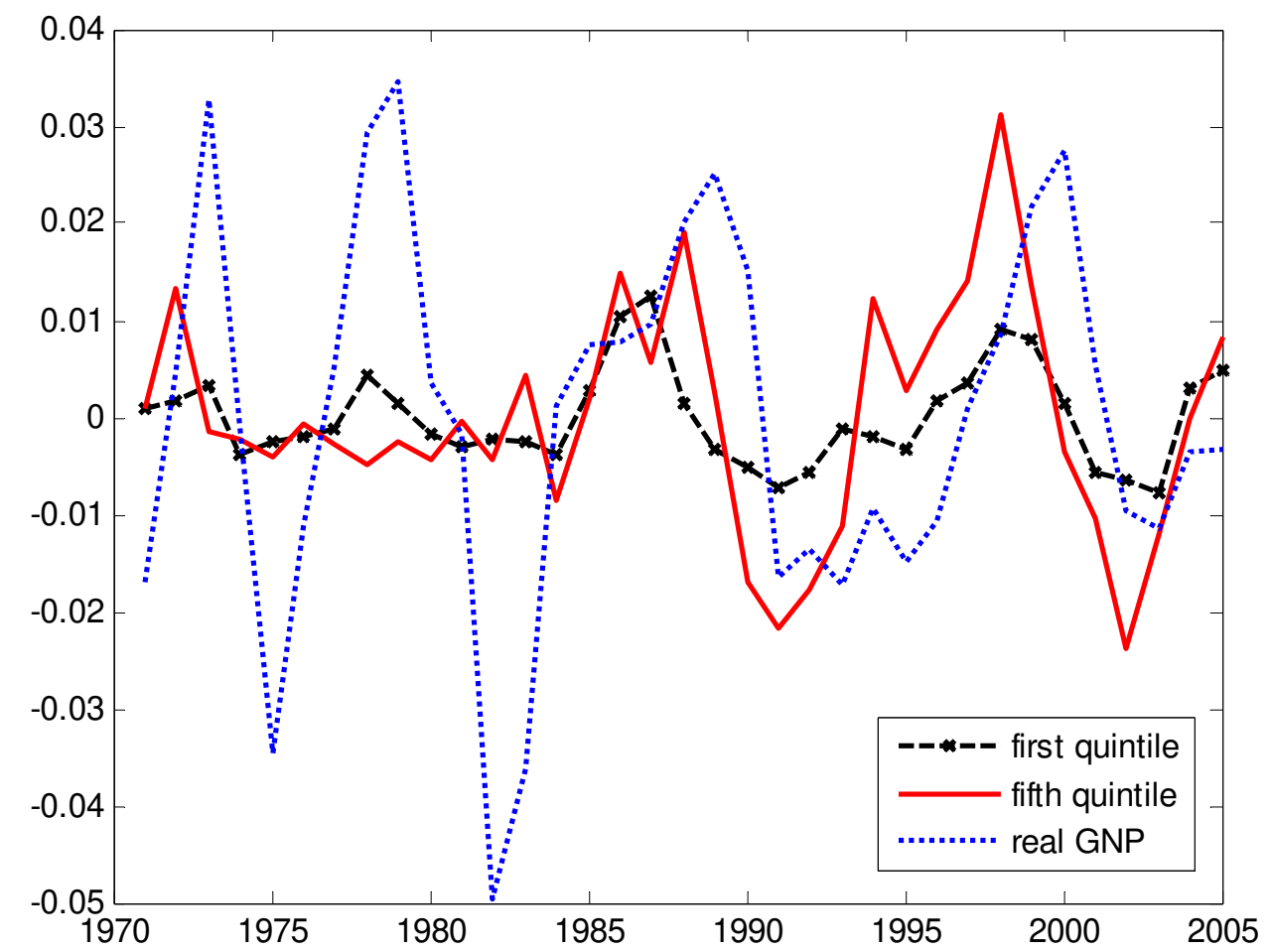

Figure 8: Capital Reallocation over the U.S. Business Cycles for Different KZ Quintiles. 